\title{
EL FENÓMENO GRÁFICO DE LA ESCRITURA CURSIVA EN NAVARRA
}

Tomar conciencia del estado actual de los conocimientos de Paleografía navarra exige una clarificación a la que sólo se puede llegar huyendo de lo meramente descriptivo. Ninguna dificultad ofrecería presentar una relación, hasta con pretensiones de exhaustividad, de estudios generales y monográficos de fuentes históricas y literarios del reino, que, naturalmente, no pueden soslayar un estudio más o menos detenido, más o menos superficial, sobre algo tan importante como la escritura en que fueron redactadas. La relativa abundacia de publicaciones, la reiterada y obligada clasificación cronológica o temática, la vinculación, casi siempre inevitable, del lenguaje escrito con el hablado, en cuanto que son vehículos de expresión del investigador con el que podría quedar oculta una realidad que no debe disimularse: penuria, escasez, carencia de publicaciones de carácter estrictamente paleográfico, desvinculado de la Historia y la Heurística. Trataremos de descorrer ese manto, aun afrontando el riesgo de no valorar debidamente trabajos de investigación valiosísimos, pero alejados de lo específico y actual en la metodología de nuestra disciplina.

Los más penetrantes estudios sobre la primitiva escritura del reino, debidos a los profesores Canellas y Ubieto ', utlizan preferentemente el método histórico-crítico para discernir fecha y personas mencionadas en documentos del siglo $\mathrm{X}$, precisando el valor de originales y copias y enriqueciendo las tesis del profesor Millares ${ }^{2}$ sobre el uso de la letra minúscula visigótica en la documentación del reino de Mavarra. Los tres documentos originales conservados, tanto el publicado por el profesor Canellas como los consignados, publica-

' A. CANELLAS, Un documento original del rey Sancho Garcés II Abarca, en "Estudios de Edad Media de la Corona de Aragón» (EEMCA) I (1954), pp. 149-192; UBIETO, Con qué tipo de letra se escribió en Navarra hace mil años?, en "Revista de Archivos, Bibliotecas y Museos» (RABM), 63 (1957), pp. 409-422; C. HERRERO, La letra visigótica en los renios pirenaicos, en RABM, 41 (1920), pp. 497-512.

'Tratado de Paleografía española, 3." ed. Madrid, 1983. 
dos y estudiados en el trabajo de Ubieto, prueban el uso de la letra «cursiva visigótica en el siglo $\mathrm{X}$, que registra una unidad gráfica en los reinos de Navarra y Aragón, semejante a la de otros estados occidentales de la Península Ibérica. Es imposible precisar, por falta de fuentes, el momento de introducción de la minúscula redonda o posada en la confección de documentos reales, cuyo primer original registra Ubieto en 1929, fecha en que, cerrando el ciclo 983-1029, cabe pensar como efectiva tal sustitución.

Nada nuevo aporta al conocimiento de la escritura del siglo XI ni mi trabajo sobre los documentos reales ni las publicaciones sobre fuentes de la época que en él recojo :.

La escritura carolina y su nuevo canon, la introducción del ductus carolino en documentos y libros de reino de Navarra, principalmente en los monasterios de Roncesvalles y Fitero, han sido estudiados en dos obras fundamentales, cuya investigación responde a las más rigurosas exigencias de la metodología actual y cuyas autoras son las doctoras Ostolaza y Monterde ${ }^{4}$.

La escritura bajomedieval ha sido estudiada en dos recientes publicaciones, aparecidas una en Pamplona y otra en Zaragoza '. En esta segunda el estudio paleográfico es un factor más de los integrantes de la «forma diplomática», cuyo estudio desarrolla ampliamente el autor. Así, en el período denominado "capeto" (1274-1328) se habla de escrituras «pregóticas y góticas, sencillas y esbeltas, de origen francés, sin tipos uniformes: ductus varios según escribas». En el período Evreux (1329-1441) se registra la «evolución paulatina de la gótica cancilleresca, desde tipos sentados a tipos semicursivos; todavía dominan los ductus muy redondeados y cligrafiados con Felipe III, pero ya se inician leves aguzamientos de astiles, alternancia de gruesos y perfiles con Carlos II; algún notario cuida mucho la caligrafía (por ej. Ceilludo, con Carlos III); finalmente, apuntan ejemplos de escritura bastarda a la moda francesa, inclinada a derecha y astiles cuneiformes».

Dar nombre y caracterizar una es escritura significa haber llegado a una

"Los documentos de los reyes de Pamplona en el siglo XI, en "Folia Budapestina», Zaragoza, 1983, pp- 7-22.

4 Isabel Ostolaza Elizondo, Colección diplomática de Santa María de Roncevalles (1127-1300), Pamplona, 1978 (tesis doctoral de la que no se publicó el estudio paleográfico que acomapañaba a la Colección diplomática); Cristina MONTERDE ALBIACH, El monasterio de Santa María de Fitero (siglos XII y XIII), Zaragoza, 1978 (con estudio paleográfico, pp. 51 128.

' García Larragueta-OStolaza, Estudios de Diplomática sobre fuentes de la época de Sancbo el Sabio, Vitoria, 1982 (estudio paleográfico pp. 160-166); CANELLAS, La cancillería del reino de Navarra des de Teobaldo I a Blanca, en J. Zurita, "Cuadernos de Historia", 47-48, Zaragoza, 1983 (pp. 71-138; hay 38 fascímiles de documentos y 12 de sellos). 
conclusión sobre su naturaleza e intentar condensar en una o dos palabras su definición. Difícil selección de vocablos que caractericen la escritura y a la vez la diferencien en otras semejantes. El Congreso de Paleografía de París 1953 quiso unificar terminologías, y lo consiguió en terreno librario con la publicación de Bischoff, Liefrinck y Battelli "; treinta años más tarde seguimos sin una obra semejante, validad para las escrituras documentales.

Utilizamos el nombre de "cursiva bajomedieval» para designar la más característica de las cursivas empleadas en el reino. Siendo la Paleografía una ciencia empírica, su investigación sigue el camino inverso al que hay que desarrrollar en una exposición sistemática, por lo que el concepto de escritura cursiva bajomedieval requeriría, antes de ser formulado, un estudio analítico previo. Lo mismo que el concepto «Paleografía navarra» puede ser considerado como avance de una conclusión, si no como una petición de principio. Trataremos de justificar el primero en lo posible, pues el segundo es más hipotético.

Mallon previene contra el prejucio de la lengua; Bartoli Langeli, contra el de la nacionalidad ( «italianità... possibile di esser giudicata limitativa rispetto a fenomeni di dimensione più amplia o viceversa arbitrariamente unificante») '; conviene indicar aquí que con la expresión "Paleografía navarra» se quiere significar un estudio del grafismo en cuya elaboración se han utilizado fuentes de ese reino. También constituiría un prejuicio, que de hecho es frecuente en muchos trabajos de investigación, acometer la caracterización paleográfica -incluso la diplómática- de documentos reales, como si su escritura constituyera una categoría diferente de la de documentos reales, como si su escritura constituyera una categoría diferente de la de los documentos particulares. Millares ${ }^{8}$ escribía: «En los documentos particulares de los siglos XIV y XV la escritura siguió una marcha semejante a la de los diplomas reales». No sólo semejante, podríamos decir, sino idéntica, y que unos mismos autores materiales, los notarios del reino, redactan tanto los documentos reales como los particulares.

Las escrituras notariales, objeto de atención preferente en este estudio, revelan que es el notariado, y muy especialmente los notarios de la Cort, el autor material de producto gráfico más característico entre las escrituras usadas en el reino de Navarra, la cursiva. Para significar el escaso relieve y significado que en el desarrollo de esta escritura tienen los documentos reales, basta observar

- Nomenclature des écritures livresques, Paris, 1954.

' MAllon, Paléographie romaine, Madrid 1952, p. 168; BARTOLI LANGeli, Ancora su paleografia e storia della scrittura, en «Scrittura e civiltà», 2, (1978) p. 289.

${ }^{8}$ Paleografía española, 1.“ ed, Barcelona, Edit. Labor, 1929, p.269. 
que uno de los más solmenes documentos expedidos por la Cancillería real, las Ordenanzas de 1 junio 1387, en nada difiere de la escritura de los documentos particulares, de que se conservan abundates ejemplos, tanto de su autor material, Simón de Nauar, como de otros notarios de muy parecidas características gráficas.

Desde finales del siglo XIII y al menos hasta comienzos XV, el notariado de la Cort, tribunal superior de justicia del reino, asume las funciones de la cancillería real: en Navarra no sólo surgen órganos de administración y gobierno que se convierten en centros de expedición de documentos al margen de la Cancillería, sino que los notarios de la Cort llegan a suplantarla .

Examinando el documento núm. 1 de este trabajo resalta, aun antes de comenzar su lectura, como más visible carácter gráfico su cursividad. La observación de las curvas envolventes de la letra «q" (líneas 1,3,4, 5, etc.); o las prolongaciones de los últimos rasgos de la «S» (ej. «sabuda», linea 1; "Sanchetz», linea 4), o de la letra "g» («otorgam», linea 2; «Domingo», linea 8) nos sitúa ante fenómenso gráficos habituales en los últimos años de la Edad Media. Lo mismo ocurre con el documento núm. 2, cuyas características prueban la semejanza del grafismo de su autor material, que escribía en Jaca, con el del anterior documento, de la comarca de Pamplona ${ }^{10}$.

$\mathrm{Y}$, sin embargo, ninguno de los dos documentos está fechado en el ocaso de la Edad Media. El navarro es de 1284; el jacetano, de 1297. Los caracteres de la escritura de la época de los Reyes Católicos aparecen inequívocamente desde las últimas décadas del siglo XIII; y, a medida que el tiempo transcurre, su presencia será cada vez más frecuente en la escritura documental. Esta escritura bajomedieval, «unas veces regular y otras con cursividad muy acentuada», ha sido llamada por Millares precortesana ".

Tanto la precortesana como la propia escritura cortesana del siglo XIV son resultado de un largo proceso de cursivización de la escritura. Dijo el profesor Floriano '": «Ningún tipo de letra, a lo largo del desarrollo total de la escritura latina en España, realiza una evolución más completa y más perfecta que la cursiva del período gótico». Esta escritura, que los manuales llaman gótica cursiva, es difícil de caracterizar de modo preciso, «dad la variedad y libertad de trazado que esta escritura ofrece», según expresión de Millares ". Nuestro estudio, que utiliza fuentes del reino de Navarra, puede colaborar a resaltar

9 Cf. García LaRragueta-Ostoloza, El documento regio navarro. Estado de la cuestión, en "Boletín de la Sociedad Castellonense de Cultura», LVIII, 1982, p. 395-469.

11) Hasta en el extremo meridional del reino, en Tulebras, se puede advertir el mismo fenómeno. Cf. AGN, Monasterios, Tulebras, leg, 14 núm. 340 (1284).

$"$ Tratado, 3. ${ }^{\circ}$ ed. Madrid, 1983, I, pp. 224-225.

12 Curso general de Paleografía, Oviedo, 1944, p 485.

13 Tratado, 3." ed. Madrid, 1983, I, pp. 225. 
similitudes o diferencias del fenómeno de la curisivización, característico de la escritura bajomedieval en los reinos peninsulares.

«No con demasiado esfuerzo -decía el profesor Floriano ${ }^{14}$ - puediera establecerse el abolengo minúsculo-carolino de esta cursiva». Efectivamente: tanto la morfología como los enlaces entre letras y el sistema abreviativo acusan claramente su procedencia de la letra francesa minúscula redonda o posada. Esto es tan fácil de observar a primera vista, que el análisis minucioso resulta superfluo. "La transformación de la minúscula diplomática en cursiva es fenómeno que se inicia en toda la Europa de escritura latina hacia los promedios de la centuria décimotercera», dice Millares "; quien añade: "a partir de los últimos años de la centuria décimocuarta, la grafía refleja una gradual transformación, que puede considerarse terminada en las postrimerías de la misma época; transformación que consistió en redondear y estrechar sus caracteres, dar forma cursiva a sus rasgueos y aumentar sus enlaces, con tendencia que, tímidamente en un principio, fue luego ganando terreno y se hizo habitual en la cursiva del período siguiente, a escribir de un solo golpe de pluma varias palabras»" ${ }^{16}$.

El paso de la precortesana a la cortesana no fue simultáneo en toda la Península Ibérica. «Mientras en Castilla las complicaciones, ligados y espirales de la letra cortesana creaban el confusionismo... Aragón deja que la evolución de la gótica se realice en la documentación privada o eclesiástica " ${ }^{17}$. ¿Y en Navarra? Unas consideraciones previas sobre conceptos fundamentales tratarán de obtener algunas precisiones.

a) Por oposición a «mayúscula», el término minúscula designa una letra encajada en una caja de cuatro líneas, a diferencia de aquélla, que usa caja de dos líneas solamente. Ambos términos no se excluyen, pues las dos escrituras tienen como carácter común el encajamiento, y su diferencia es sólo la clase de caja (espacio limitado por dos líneas paralelas que indican y enmarcan las dimensiones máximas de altura, en las mayúsculas, y del cuerpo de la letra, en las minúsculas).

Usar minúsculas indica una búsqueda de armonía, procurando dotar de la misma altura a todas las letras. Por el simple hecho de serlo, toda minúscula significa un intento de caligrafismo. Pero en el caligrafismo hay grados. Por ejemplo, la letra de muchos documentos notariales navarros es encajada, pero nadie la calificaría de bella; regularidad en la ejecución y belleza son criterios de clasificación de escrituras que están próximos, pero pero no se pueden identificar. La bella letra del notario Juan Miguel, de Pamplona, o la de Sancho Garcés

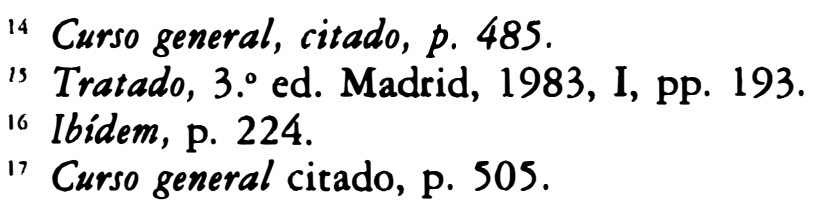


de Elcano, de las que damos muestras, no se pueden comparar con las también encajadas, pero trazadas con evidente descuido por otros notarios contemporáneos de ellos.

b) Hay un "ductus» general de la escritura y un "ductus» particular propio de la ejecución de cada letra, que Cencetti designa como "tratteggio» ${ }^{18}$. El aprendizaje de la escritura supone copiar movimientos de la mano y proporciones de los trazos; no obstante, no pueden diferenciarse dos escrituras sólo porque tengan ductus diferentes. La letra del apéndiz, aun intentando asimilar los caracteres de la del maestro, puede diferir considerablemente de ésta. Un mismo ductus puede producir letras diferentes ${ }^{19}$. Un ejemplo claro es la letra del notario pamplonés Miguel López de Zandio, cuyas muestras librarias son aparentemente tan distintas de las documentales (núm. 5 a 8 de nuestro apéndice) ${ }^{20}$.

De nuevo el caligrafismo: las primeras muestras de cursividad aparecieron en la séptima década del siglo XIII: entre 1170 y 1180 comienzan a verse incurvaciones en las astas de las letras minúsculas posadas caronilas, hacia la derecha las superiores, hacia la izquierda las inferiores. Comenzaba a alterarse la regularidad en la ejecución de aquella "vollendere Minuskel», "minúscula perfecta" de Lorhmeyer, caracterizada por la verticalidad de las astas, la armonía y proporción de las letras, aisladas, posadas, de tal sobriedad en el trazo y perfección en el conjunto que los humanistas creyeron ver en ellas «la majestad de la letra antigua» de que hablaba Petrarca, confundiendo letra carolina románica del siglo XII con la escritura clásica de los romanos ${ }^{21}$. Sería abusivo limitar la belleza de una escritura a una ejecución lenta y cuidadosa. La pericia y profesionalidad del notariado de la Cort en Navarra logra conciliar la belleza de la letra con la rapidez en su ejecución. Y eso no solo ocurrió en la Baja Edad Media; puede servir de ejemplo la evidente resonancia caligráfica de la escritura cursiva ondulada visigótica.

c) El término cursiva significa escritura ejecutada con ductus rápido; se opone a escritura posada o sentada. Su definición ${ }^{22}$ es: «un genre, c'est catégorie d'écriture, et cette catégorie était tout d'abord en usage dans la hiérarchie de l'administration. Le fait qu'on rencontre cette écriture cursive dans une forme stylisée nous donne la preuve qu'on peur bien imaginer une écriture cursive qui soir en même temps une écriture posée». La paradoja pone

${ }_{18}$ Lineamenti di storia della scrittura latina, Bologna, 1954, p. 52.

19) F. GASPARRI, Écriture de chartes, écriture de livres, en "Gazette du livre médiéval", 2 (1983) $p$ p. 4-6.

"" GARCÍA GRANERO, "Vidal Mayor", versión romanceada navarra de la "maior compilatio" de Vidal de Canellas, "Anuario de Historia del Derecho Español» (1980), pp. 243-264.

2I STIENNON, Paléographie latine du Moyen Age, París, 1973, p. 110.

"Nomenclature de écritures livresques, citada en n. 6, p. 19. 
de relieve la compatibilidad de la rapidez con la perfección lograda por el hábito, el ejercicio profesional, el oficio; los notarios, profesionales de la escritura, son capaces de lograr sin merma de la rapidez una escritura bella. La progresiva organización de la administración del reino, singularmente en el reinado de Carlos II, origina un espectacular aumento en la producción de documentos ${ }^{23}$. Más que la voluntad del otorgante o autor jurídico de éstos, la obligación administrativa de redactar tal o cual documento es el punto de partida de la génesis de estos documentos; el protagonismo pasa del autor jurídico al autor material.

d) El grafismo más generalizado en la Baja Edad Media suele recibir en los reinos hispánicos el nombre de cursiva gótica ${ }^{24}$. Llamarla «minúscula cursiva», además de distinguirla de la "minúscula posada» (minúscula diplomática, letra de privilegios, letra de juros), hace referencia a un canon de lo que los humanistas llamaron «letra moderna» ${ }^{2 s}$. El paleógrafo Cencetti llama letra cannonizzata a la escritura de letras espaciadas, armónica en sus dimensiones en sus dimensiones y proporción, caracterizada por la alineación regular, exactitud en el trazado y simplicidad en los singnos gráficos ${ }^{26}$. Es escritura opuesta a la denominada -sobre todo por los italianos- «scritura usuale», que se distingue, como decía Gerson, por sus rasgos superfluos (tractibus superfluis). La nomenclatura intenacional acepta el adjetivo "currens» para acompañar a los sustantivos "textualis», "cursiva» y "bastarda»: el término podría oponerse tanto a la escritura con pretensiones caligráficas como a la escritura "cannonizzata» ( ffactice» en Francia). Si el criterio de clasificación «belleza» la puede distinguir de las escrituras caligráficas, el criterio "uso» puede diferenciar la escritura "currens» o "usual» de las canonizadas (monumental, epigráfica, libraria solemne): la letra usual no se suele ajustar a modelos, ni siquiera en ocasiones a un mínimo encajamiento. Es difícil caracterizar un «canon». Se suele atender preferentemente a la morfología ${ }^{27}$, lo que tiene la limitación de establecer una «letra tipo», síntesis de las conservadas, pero que sólo existe como idea, nunca completamente realizada por los escribas ${ }^{28}$.

e) Cuando se habla de "canon gótico» o de «escritura gótica» no se indica una nueva categoría o género de escritura, distinta de la carolina o francesa. Es un nuevo modo de ejecución de ésta, mediante un instrumento

${ }^{23}$ García larragueta-Ostoloza, O. C. en n. 9, pp. 445-455.

${ }^{24}$ FloRiano, Curso general, citado, p. 485. 251.

25 F. GASPARRI, L'enseignement de l'écriture, en «Scrittura e civiltà», 3 (1979) p.

${ }^{26}$ Lineamenti di storia, ya citada, p. 55.

27 Descripción minuciosa, Floriano, Curso general, pp. 487-500.

${ }^{28}$ GILISSEN, L'expertise des écritures médiévales, Gand, 1973, pp. 42 y 48. 
nuevo, la pluma cortada oblicuamente a su eje ${ }^{29}$. Hay una marcada preferencia por las letras fuertemente contrastadas, buscando la alternativa gruesos-perfiles con fines estéticos: la fractura es el principal motivo o elemento caligráfico de la época. Puede servir de ejemplo la caligrafía de los notarios Juan Miguel, de Pamplona, Sancho Garcés de Elcano o Sanz de Iracheta.

Desde 1151 recoge ejemplares de "gothica primitiva» o "carolinogothica» el doctor Kirchner ${ }^{30}$; fuera del ámbito librario, fuentes documentos desde finales del siglo XI atestiguan el uso del nuevo instrumento escriptorio ${ }^{31}$. Es corriente llamar góticas a las escrituras bajomedievales, atendiendo a ello; no sería erróneo, atendiendo a su origen, morfología y sistema abreviativo, denominarlas francesas, aunque los manuales de Paleografía distinguen en la Península Ibérica la letra gótica de «albaláes» de la «letra de privilegios», pervivencia bajo medieval del caligrafismo carolino, que también se puede observar en los diplomas de los reyes aragoneses, escritos en la llamada minúscula diplomática o letra «catalana aragonesa».

f) Escribía el profesor Floriano: «la invasión de la cursiva en el campo de la libraria no es un fenómeno nuevo en este sector del campo paleográfico... La cursiva empleada en los libros del siglo XIV apenas si se diferencia de la utilizada para los documentos ${ }^{32}$. Se puede considerar artificiosa esa separaciuón de escritura libraria como acategoría distinta de la documental; en definitiva, como muestra el ejemplo citado del notario Miguel López de Zandio, los notarios del reino no sólo dominan con profesionalidad las escrituras caligráficas, que usan a la vez que otras más "currentes», sino que son políglotas, a juzgar por los diversos idiomas que emplean en la redacción de sus documentos (latín, romance navarro, francés, occitano, etc.) Millares distingue tres tipos de letras góticas, de diferente grado de cursividad, observables tanto en libors como en documentos ${ }^{33}$. También podraían registrarse en escrituras del reino de navarrra, si bien la grande influencia de la letra bastarda en los documentos notariales navarros da a muchos de éstos una fuerte carga de caligrafismo, que podría esperarse como más propia en la escritura de libros.

Resumiendo: a pesar de la simplificación que siempre supone adjudicar un nombre a una determinada escritura, los documentos navarros prueban que en su grafía el carácter de «minúscula» es siempre más visible que el de «cursiva»,

29 BOUSSARD, Influences insulaires dans la formation de l'écriture gothique en «Scriptorium», 5, 1951, pp. 238-264; GILISSEN, O. C. fig. 1, 2 у 3.

30 Scriptura gotbica libraria, Oldenburg, 1966.

3 CenCETTI, Lineamenti di storia, citada, p. 256.

32 Curso general, citado, p. 484.

3 Tratado, 3." ed. Madrid, 1983, lám. 324, 326 y 346-348 (tipo A); lám. 327 y 349-350 (tipo B); lám. 328, 352, 353 y 354 (tipo C). 
que no les falta. Hasta las muestras más alejadas del caligrafismo, como puede ser la escritura del notario Lope Miguel, de Villava, no deja de mantener el encajamiento y de presentar cierta regularidad en la ejecución, aun siendo ésta irregular y de temblorosos trazos. Si la letra de privilegios o la de juros pueden ser consideradas como una reacción a la cursividad imperante, ya que su ejecución significa un esfuerzo del escirba para solemnizar ciertos documentos, destacándolos de los que no le merecen por su categoría esa especial consideración, la redacción de documentos navarros fen la Baja Edad Media muestra en general una consciente moderación en el uos de la letra cursiva que nunca llegó a ser totalmente «currens». Hay que pensar en una influencia caligráfica adquirida por el aprendizaje de la escritura en diferentes universidades europeas, pues consta por estudios de Goñi Gaztambide que no sólo frecuentaron las hispánicas ${ }^{34}$. Esa letra universitaria, estudiada por Hajnal y Mezey ${ }^{35}$, es el más representativo producto cultural de la Baja Edad Media en el terreno del grafismo. Es un estilo internacional lorado por escolaridad sistemática, quizá exigida al resto del notariado navarro por sus examinadores, los notarios de la Cort, que progresivamentese fueron distanciando de los demás, constituyendo una élite, hasta en la caligrafía ${ }^{36}$.

Poulle haba de una escritura de la cancillería real francesa, a fines del siglo XIII, mezcla o compromiso entre la letra libraria y la «epistolaris» de la época de San Luis, de módulo reducido y cierta cursividad, a la que llama «écriture mixte" ". Un modelo librario caligráfico semejante parece estar siempre presente en la letra cursiva de los notarios navarros. Si no se conserva en Navarra ningún tratado de caligrafía, como el descrito por F. Gasparri en la abadía de Melk hacia $1420{ }^{38}$, sin embargo un tipo de letra «semirotunda o semiquadrata (quod idem est)", a mitad de camino entre la caligrafía prerrenacentista y las tradiciones góticas, era conocido por aquéllos; se pude hablar de una «littera curiensis» en Navarra.

Aplicando al estudio de la cursiva bajomedieval los supuestos prácticos de análisis extraídos de documentos notariales del reino de Navarra, se obtienen estas características generales de la morfología y ductus de la misma:

1. Duplicación del primer trazo en letras iniciales de palabra. Lo ordinario es que afecte al trazo vertical, ejecutado de arriba abajo; aunque no faltan

${ }^{34}$ La formación itelectual de los navarros en la Edad Media, 1122-1150, "EEMCA», X (Zaragoza, 1975), pp. 143-303.

"L'enseignement de l'écriture aux universités, Budapest 1959 (2." ed.).

- García larragueta-Ostoloza, O. C. en n. 9, pp. 451-455.

37 Paléographie des écritures cursives, Genève, 1966, p. VI.

${ }^{38}$ F. GASPARRI, Enseignement et techniques de l'écriture du Moyen Age à la fin du XVIe siècle, en «Scrittura e civiltà», 7 (1983) p. 211. 
ejemplos de duplicación de trazos horizontales, como en las letras B, D y Q. La costumbre hace que en lugar de repetir su único trazo vertical, se dupliquen las letras inicales F, R y S. Duplicación de la letra que puede considerarse como equivalente a la duplicación de su trazo inicial, por lo que parece oportuno tener en cuenta esta equivalencia y elevarla a norma de transcripción: en ésta es innecesaria la duplicación de letras iniciales (Rrodrigo, Ffernando), por tener su origen en la habitual modificación de una parte del signo que las representa. Pueden verse los siguientes ejemplos:

$C=$ Ciçir (doc. 1 lin. 3 y 10); Comendador (doc. 6 lin. 7); Çandiu (doc. 8 lin. 10); Carta (doc. 9 lin. 1 y 3).

$\mathrm{D}=$ Diumenge (doc. 18 lin. 3$)$

$\mathrm{E}=$ Eyllos (doc. 3 lin. 1); Et (doc. 5 lin. 9); Era (doc. 8 lin. 9); Echauri (doc. 9 lin. 1).

$\mathrm{G}=$ Guarcia (doc. 4 lin. 2).

$\mathrm{M}=\mathrm{M}$ (doc. 4 lin. 7); Martin (doc. 9 lin. 1); Mil (doc. 12 lin. 3); May (doc. 18 lin. 3).

$\mathrm{N}=$ In (doc. 1 lin. 1); Nauarra (doc. 6 lin. 12); Notario (doc. 11 lin. 8).

$\mathrm{O}=$ Otorgam (doc. 6 lin. 2); Obispado (doc. 9 lin. 2); Ont (doc. 10 lin. 1).

$\mathrm{P}=$ Pere (doc. 1 lin. 3); Prior (doc. 3 lin. 5); Pampalona (doc. 8 lin. 11); Pascha (doc. 18 lin. 3).

$\mathrm{R}=$ Ronçasualles (doc. 3 lin. 1 ).

$\mathrm{T}=$ Testimonis (doc. 1 lin. 8); testes (doc. 4 lin. 4); trezientos (doc. 11 lin. 7).

2. Progresivo aumento del ligado entre letras, algunas de las cuales nunca habían enlazado con la siguiente en escrituras anteriores a la Baja Edad Media, como ocurre con la «i» (cf. doc. 3).

Pueden servir de ejemplo los enlaces de la letra «d», como "demandauen» (doc. 4 lin. 4); «dita» (doc. 4 lin. 6); «donadio» (doc. 14 lin. 3); «dicha » (doc. 14 lin. 6).

Por cierto que la letra «i» nunca va puntuada. Lo mismo que la «r» y otras letras admite signos diacríticos, no sólo cunado se trata de indicar repetición, sino incluso yendo sola. La puntuación la suele llevar, en cambio, la "y» griega: ej. "paneaygat» (doc. 1 lin. 9); "Garceytz» (doc. 12 lin. 4); "Marya» (doc. 15 lin. 5 y 6). Ejemplos de signos diacríticos: «sarrayller» (Doc. 12 lin. 12); "Xemenité» (doc. 12 lin.2).

Las letras "C» y «t» suelen enlazar con la que sigue mediante un trazo situado en la parte superior de la caja de escritura, que con frecuencia genera ductus imitativos, haciendo en ocasiones dificíl la lectura. Algunas veces se 
prolonga, constituyendo un auténtico rasgo superfluo. Ejemplos: «cauayllero» (doc. 10 lin. 4); "clamatz» (doc. 12 lin. 1); "partidas» (doc. 13 lin. 4); «cinc» (doc. 16 lin. 3).

3. Rasgos prolongados innecesariamente, especialmente cuando son finales de palabra. Ejemplos: signos abreviativos de los documentos 7 y 8 (este fenómeno de la prolongación innecesaria del trazo es paralelo a la pérdida de su función abreviativa: con frecuencia es superfluo, colocado sobre palabras redactadas con todas sus letras); rasgos inferiores de las letras «g» $\mathrm{y}$ «s» (doc. 1, 5 y 6, passim); letra "s» final de palabra («omes», doc. 1 lin. 1; «uendimes", doc. 1 lin. 4; «uos», doc. 1 lin. 5 «mes», doc. 1 lin. 10; «testis», doc. 1 lin. 12).

4. Creciente rasgueo levógiro, principalmente visible en la curva envolvente. Ejemplo: «que» (doc. 1, passim; doc. 8 lin. 7); «frayre» (doc. 4 lin. 6); «Hynieguo» (doc. 4 lin. 5); etc.

5. Modificaciones en la morfología de varias letras, debidas a la rapidez creciente del ductus y a exigencias del ligado. Así ocurre con:

$A=$ Junto a la minúscula ejectuada con dos glopes de pluma aparecen otras con tendencia a hacerlas de un solo golpe, con lo que la letra queda abierta por abajo. Ejemplo: «carta» (doc. 12 lin. 3); «a» (doc. 17 lin. 1). De la «a» mayúscula (ejemplo: «a totz», doc. 1) procede la «a» bastarda con gran desarrollo de la curva inicial del tercer trazo. Ejemplos: «a carta» doc. 10 lin. 3; "a las» doc. 13 lin. 3. Incluso aparecen, con anticipación temporal grande, auténticas formas de esa letra en escritura cortesana.

$\mathrm{C}, \mathrm{T}$ y $\mathrm{E}$ simplifican su trazado, reducido a 2 trazos, que originan frecuentes posibles confusiones de lectura. Ejemplo: «recebido... dita orden» (doc. 6 lin. 6).

$\mathrm{D}=\mathrm{Su}$ trazo ascendente, que desborda el margen superior, continúa en otro descendente, en sentido contrario, cerrando un espacio u ojo. Ejemplos: "don Domingo" (doc. 1 lin. 8); varios más, doc. 6 lin. 10.

$\mathrm{G}=\mathrm{El}$ mismo fenómeno en el último trazo, paralelo al margen inferior de la caja de escritura (curvas contrapuestas); iniciación, además, de la «g» de lineta, aunque no es frecuente. Ejemplo: «signum» (doc. 1 lin. 11).

$\mathrm{P}=$ Ductus imitativo en el $2 .^{\circ}$ trazo, que, en oposición al ductus normal, resulta ascendente. Ejemplo: "public» (doc. 8 lin. 11).

$\mathrm{R}=$ Cursividad creciente; subsisten la minúscula ("Gracia», "Maria», doc. 1 lin. "1), la "quadrata» («prior», doc. 3 lin. 5; «libras», doc. 6 lin. 9) y la de 3 trazos («renunciam», doc. 8 din. 7; «rasura», doc. 13 lin. 5).

$\mathrm{S}=$ Evolución hacia la «s» sigmática («sia», doc. 4 lin. 4; son testimonis», doc. 5 lin. 7; «entramps», doc. 8 lin. 5). Subsiste la «s» larga («puissa», doc. 1 
lin. 7; «seten», doc. 13 lin. 5) y la de doble trazo curvo («sobredichas», doc. 9 lin. 3; «sessanta», doc. 11 lin. 7; «Sagues», doc. 13 lin. 6; «deles» doc. 17 lin. 5).

6. De los enlaces y abreviaturas, idéndicos a los descritos en manuales, cabe destacar el signo «et», a veces inicio de curva envolvente (ejemplo: doc. 2 y $5)$. Su transcripción es variable: hay notarios que lo escriben siempre con - $t$ (et), aun en textos romances; otros siempre «e»; algunos «et» ante palabra que comienza en vocal y «e» ante inicio en consonante. La posible norma de transcripción estaría en función del uso de cada notario cuando no abrevia la conjunción copulativa.

\section{SANTOS GARCÍA LARRAGUETA Universidad de Navarra}

\section{RÉSUMÉ}

Aprés un examen de la bibliographie peu abondante sur l'écriture cursive dans les sources du règne de Navarre, et des précisions terminologiques sur la définition et les caractéristiques de cette écriture, on signale le rôle important que joue le notaire et particulièrement les notaires de la "Cort" dans le développement de l'écriture, et ceci grâce à la supériorité de leur technique. L'auteur de cette étude examine l'apparition de l'écriture "pré-courtisane» et le passage de celle-ci à la "courtisane", en signalant les analogies et les différences avec les chancelleries et les études de notaire du reste de la péninsule. Le travail se termine par une exposition systématique des caractéristiques de l'écriture cursive du bas Moyen Age employée par les notaires de Navarre; ces caracteristiques justifient les noms que l'on donne à cette écriture. On trouve, enfin, 16 fac-simili à partir desquels ont été analysées les caractéristiques de ces phénomènes graphiques.

\section{SUMMARY}

After a profound study of the scarce bibliography on cursive script in sources of the reign of Navarra and of more terminology details on the definition and characters of this script, we mention the preponderant role -in the development of this type of writing- of the body of notaries and, specially, of the notaries of the "Cort" by their talent in the writing techniques. The author of this study examines the appearance of the "pre-courtesan" character and the change towards the "courtesan" type, underlining similarities and differences between these chancelleries and 
the notary's office and with the ones of the rest of the peninsula. The author ends the study with a systematic exposition of the characteristics of the early medieval cursive script used by the notaries in Navarra, characteristics that justify the names given to this type of script. The author adds sixteen facsimiles thanks to which we have been able to analyse the graphic phenomena. 


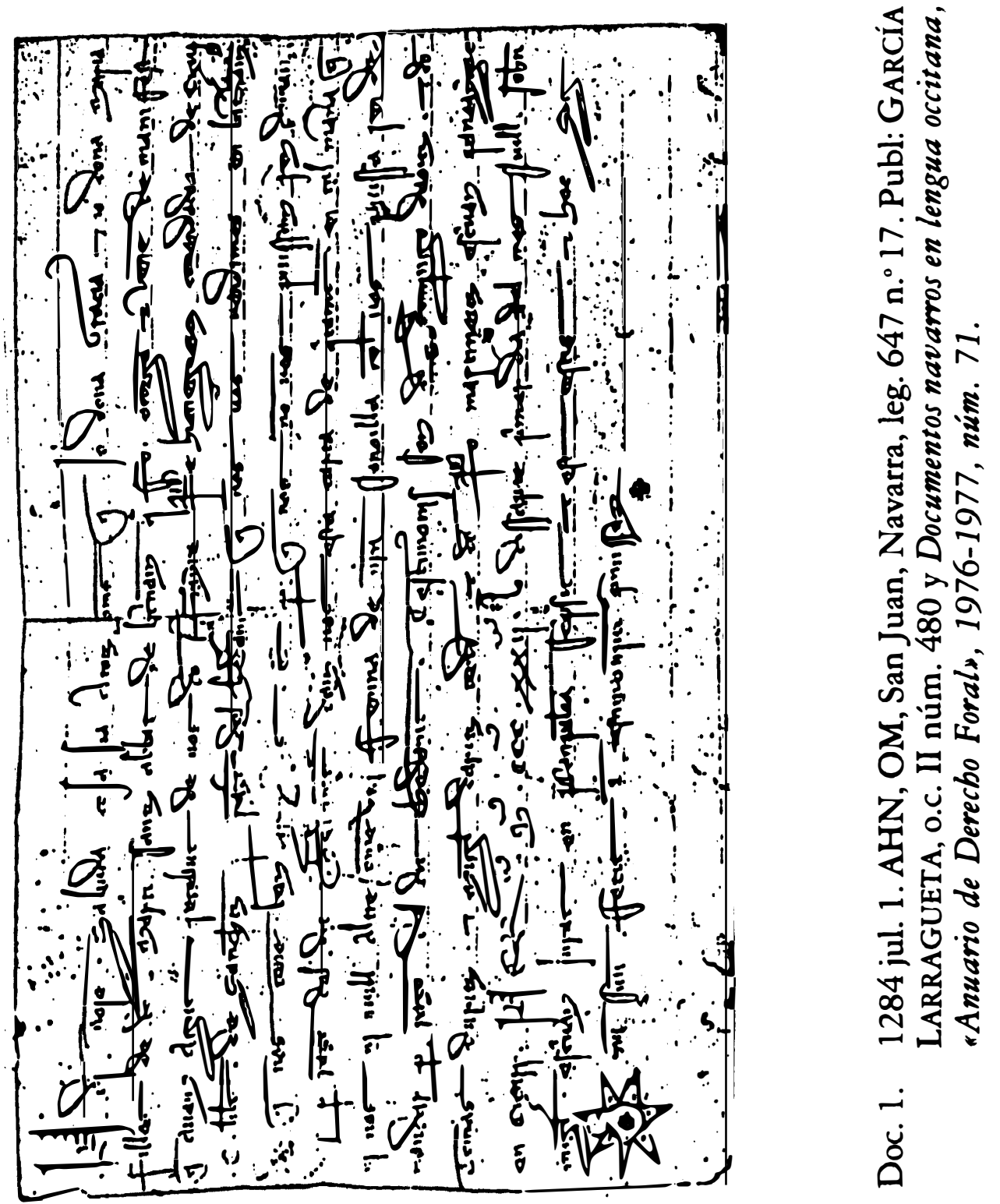




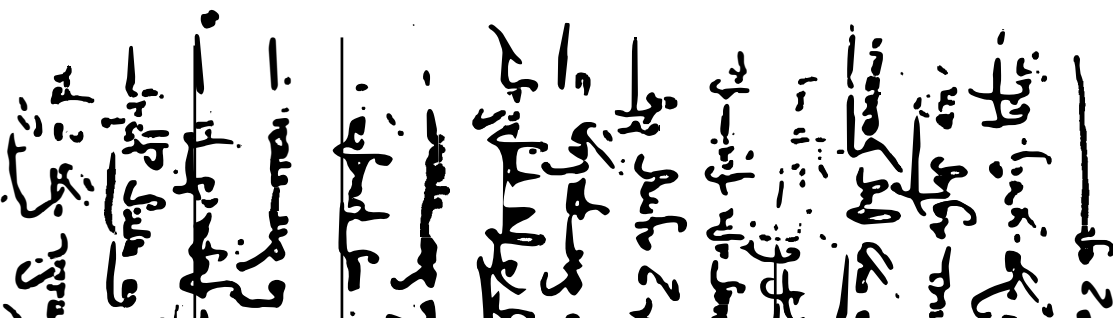

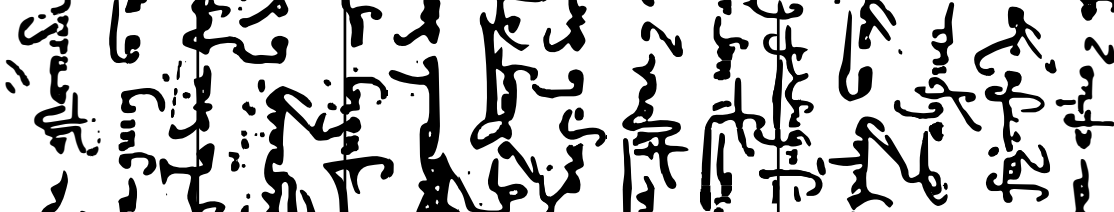

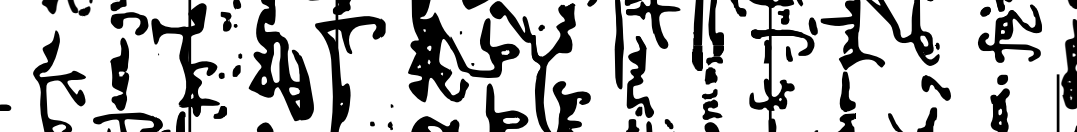

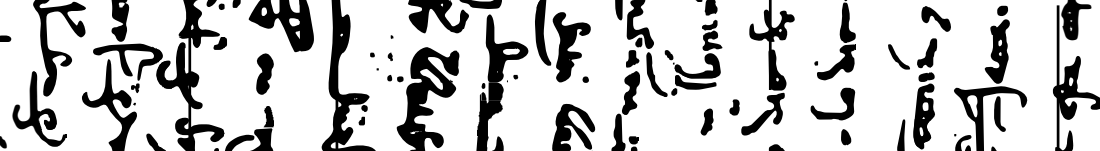

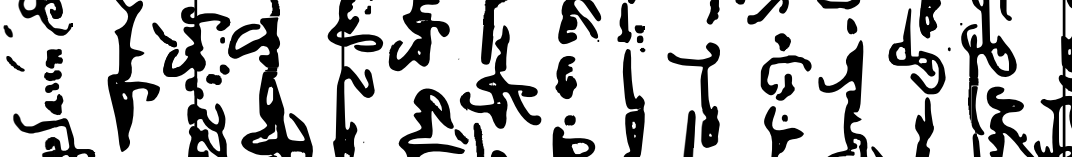

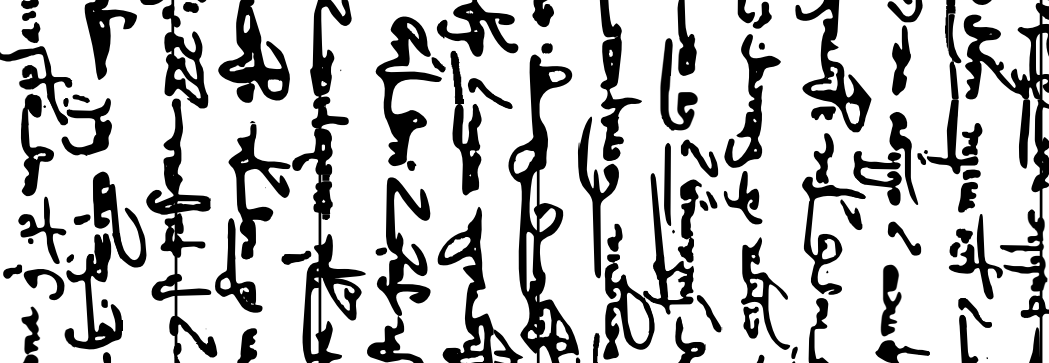

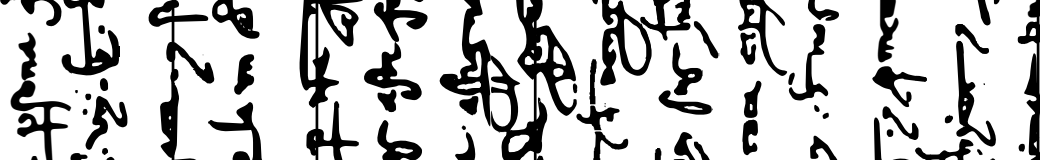

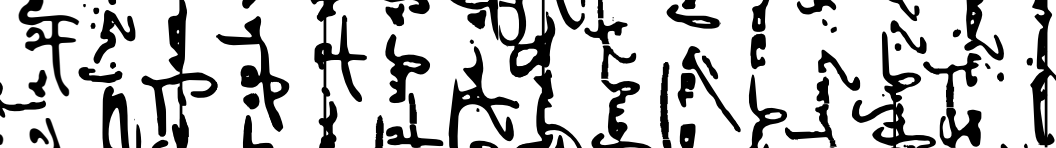
C o 60 年 A 50 ?

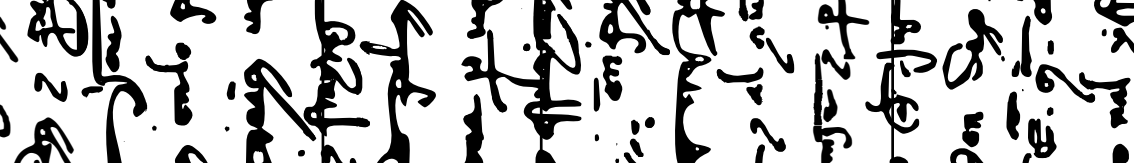
of है कीकी

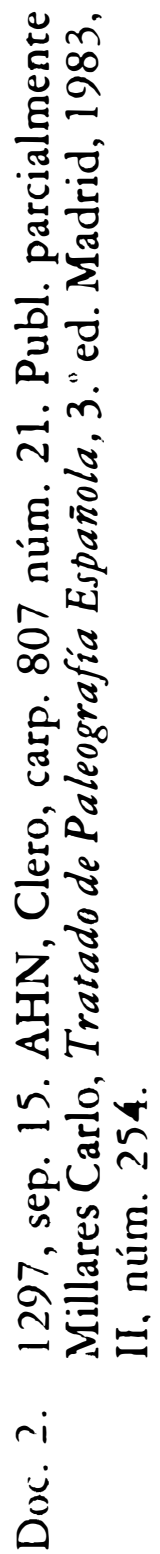


$3-0.00$

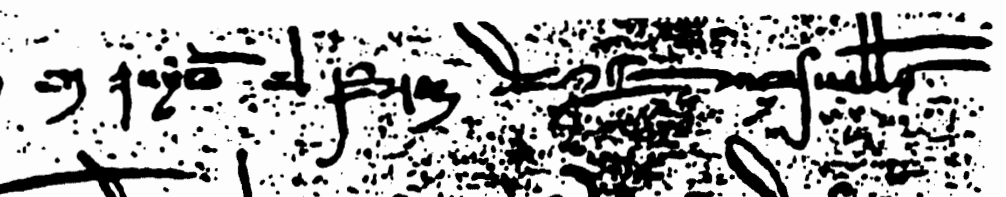

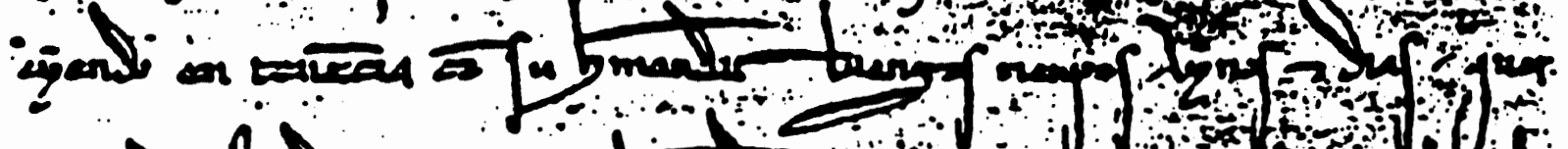

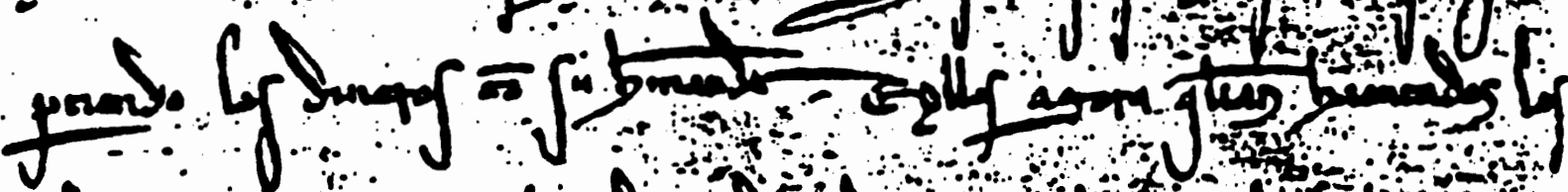

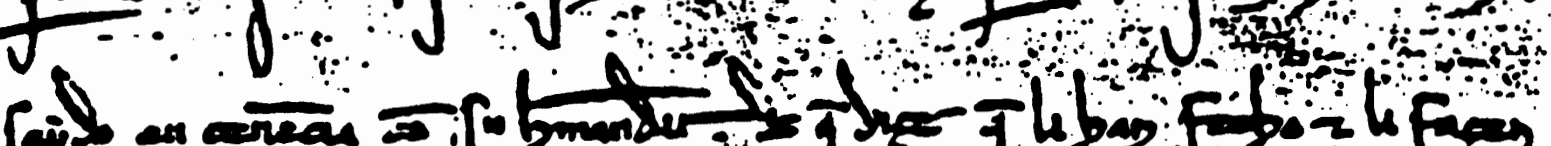

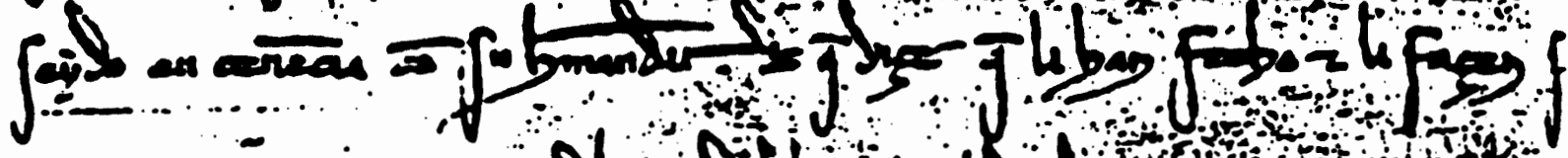

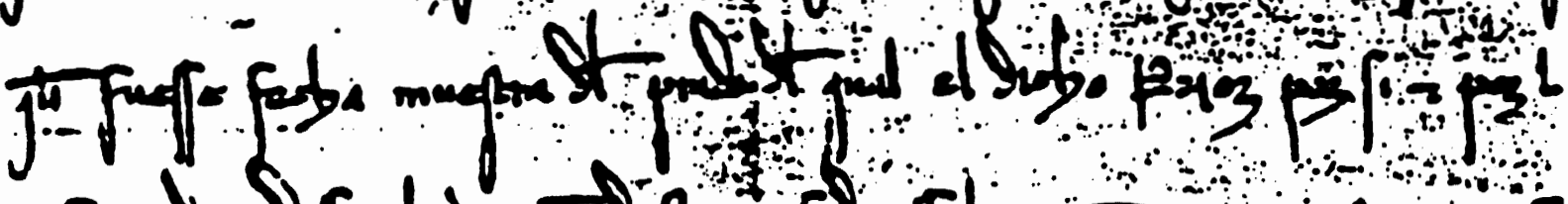

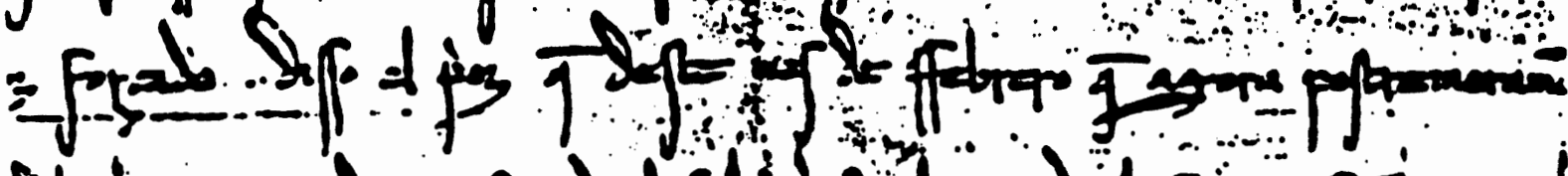

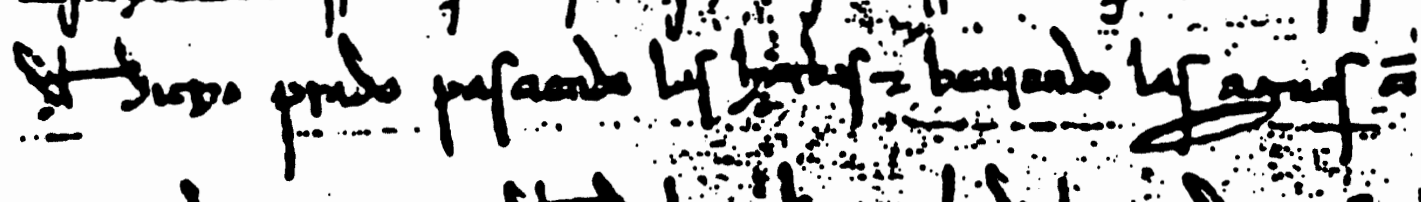

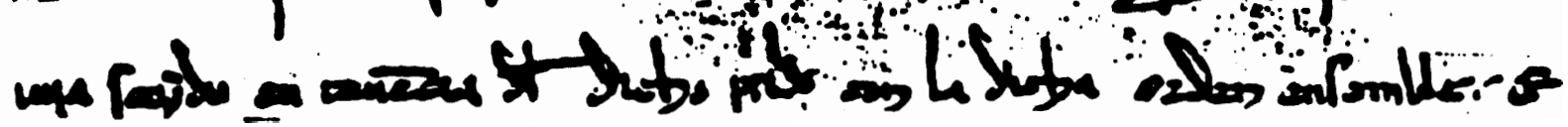

Doc. 3. 1299, mayo, 7, AGN, Clero, Roncesvalles, leg. 48, núm. 1136. Notario: Jimeno Martínez de Gallinienzo.

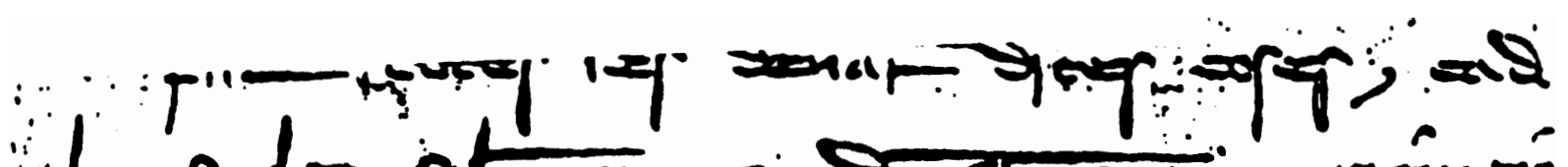

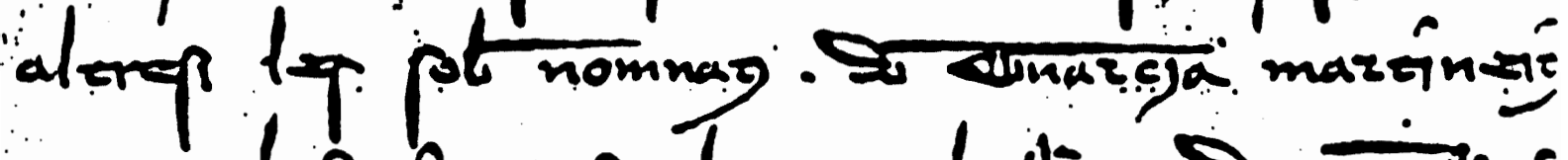

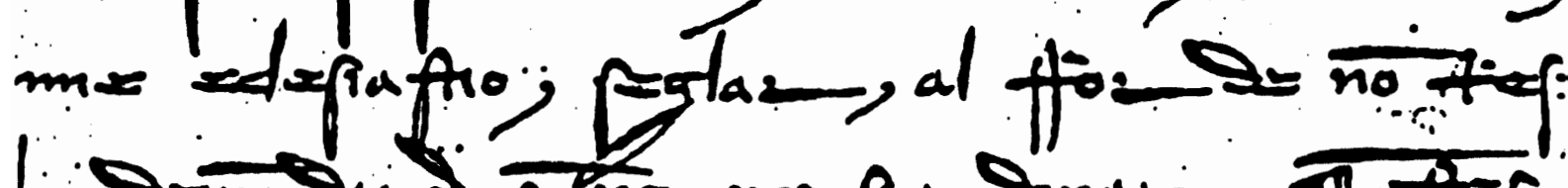

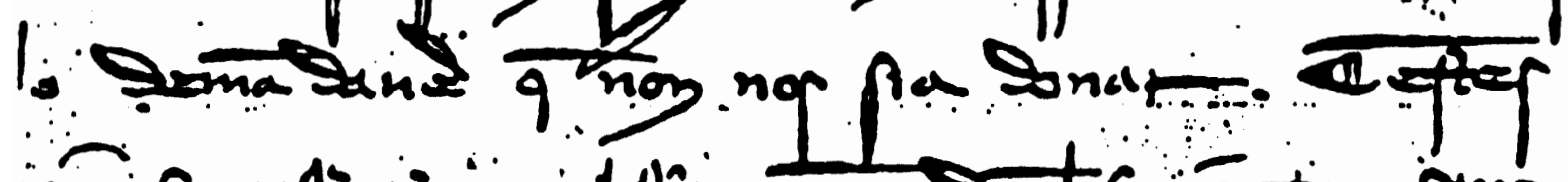

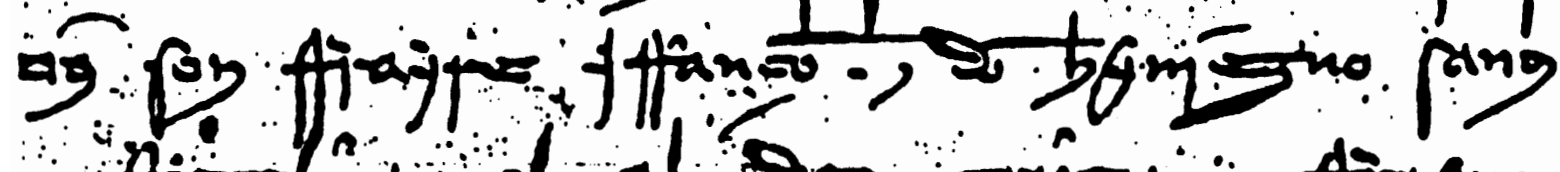
कि s.noguthe

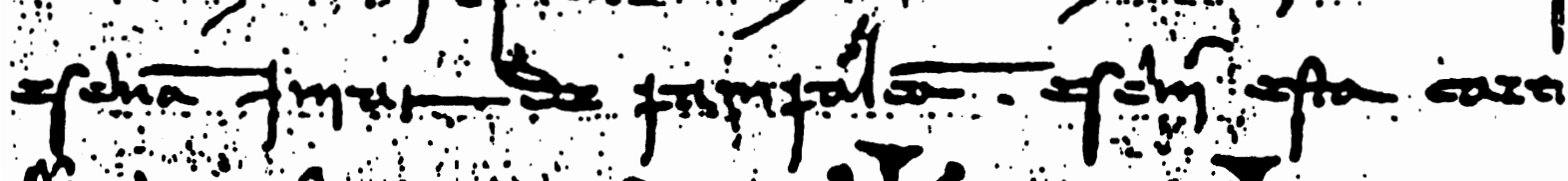

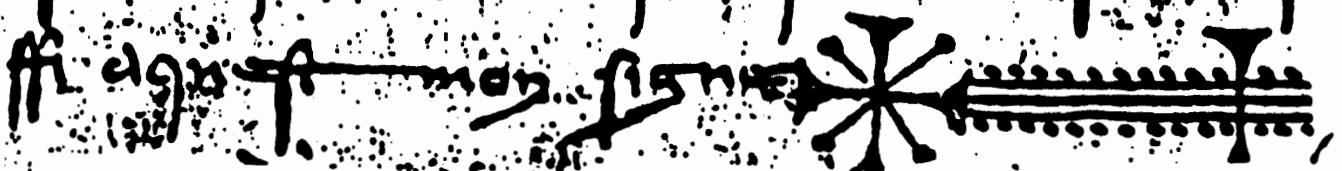

Doc. 4. 1306, abril. AGN, Clero, Roncesvalles, leg. 51, núm. 1215. Notario Pere Arnalt. 
inf

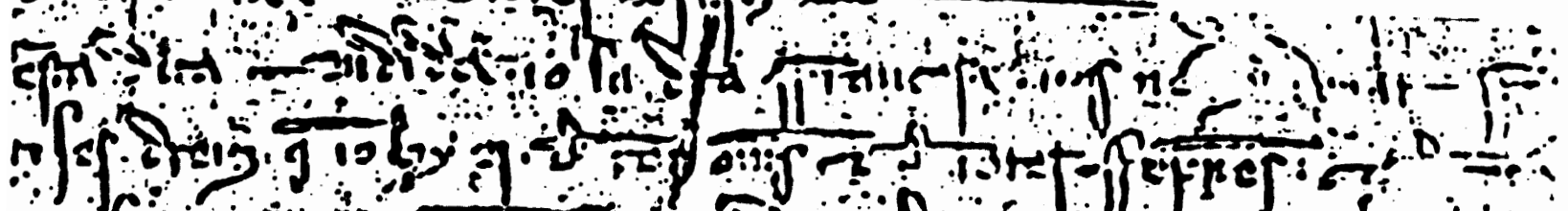

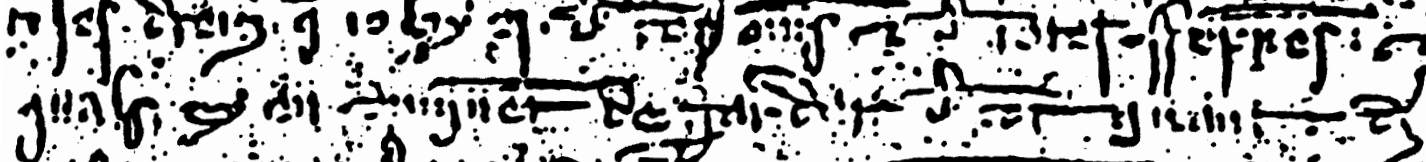

- os mbich

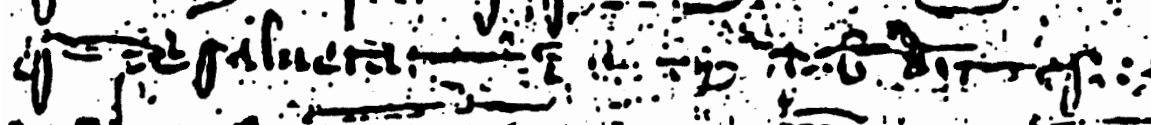

$\because$ raprinto od d d

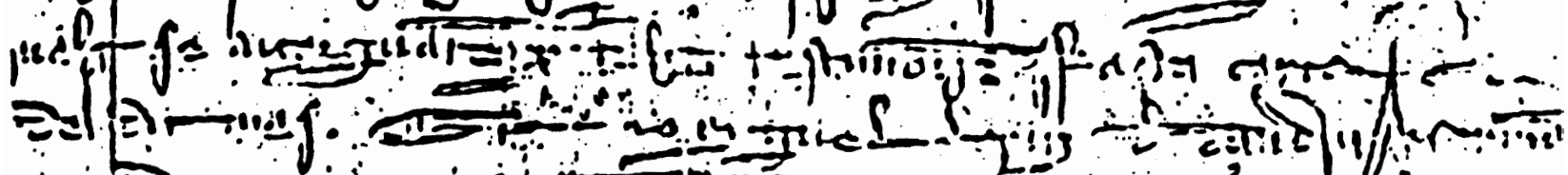

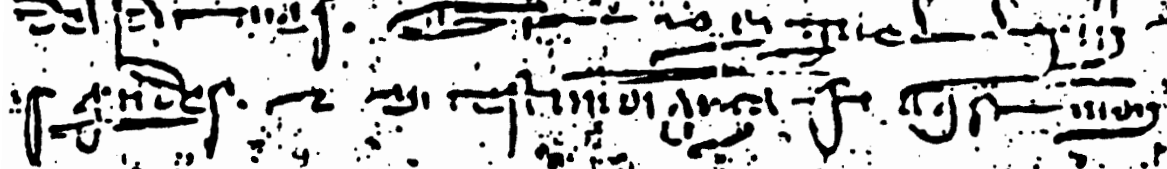

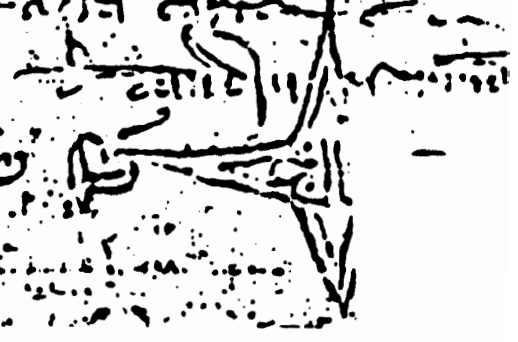

Doc. 5. 1297, abril, 10. ACP, Prior 32. Publ. GarCía Larragueta, Documentos, núm. 100.

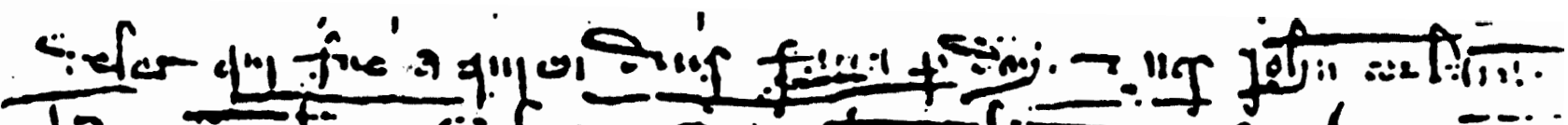

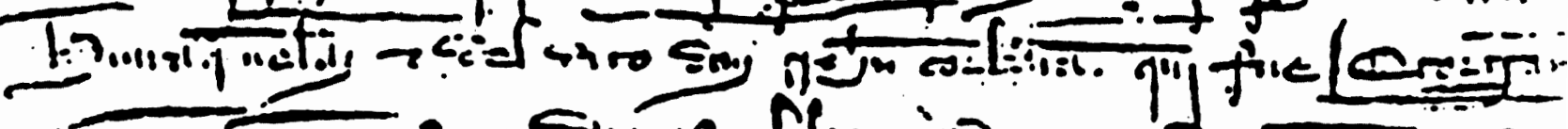

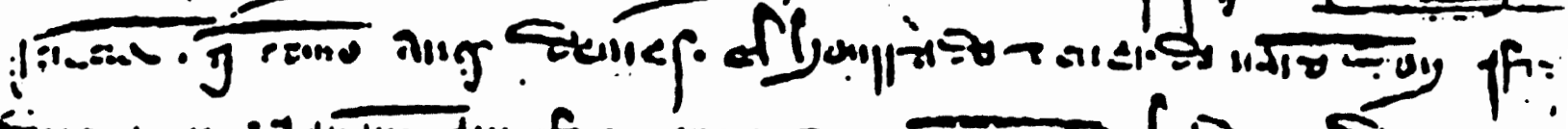

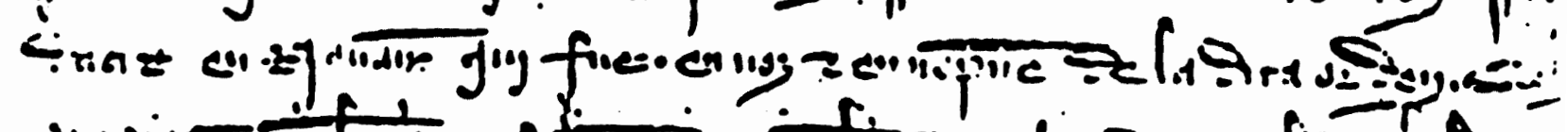

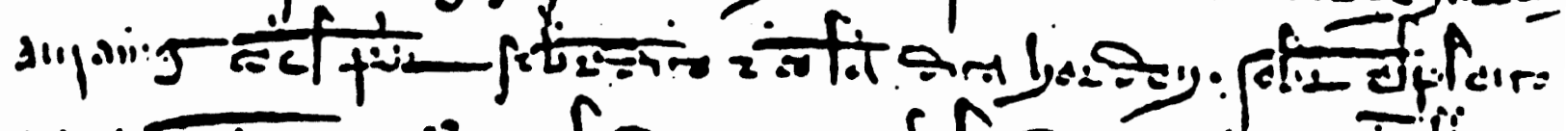
nun.l. fin:

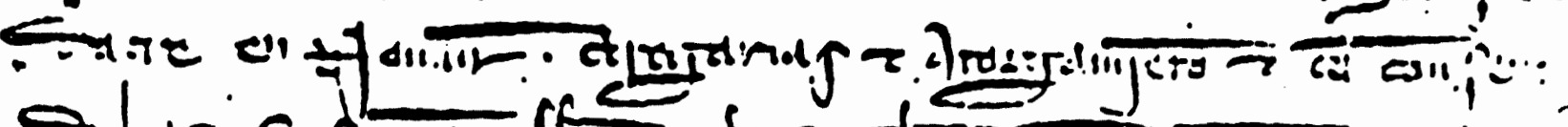

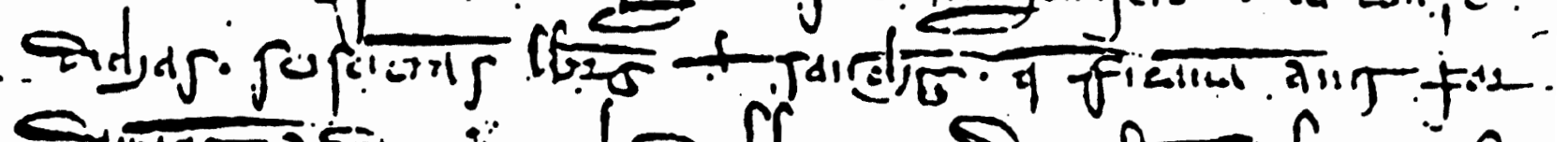

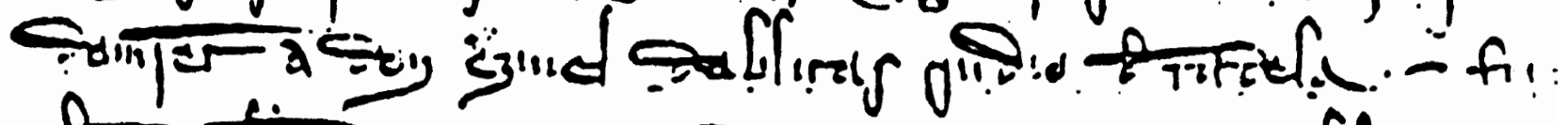

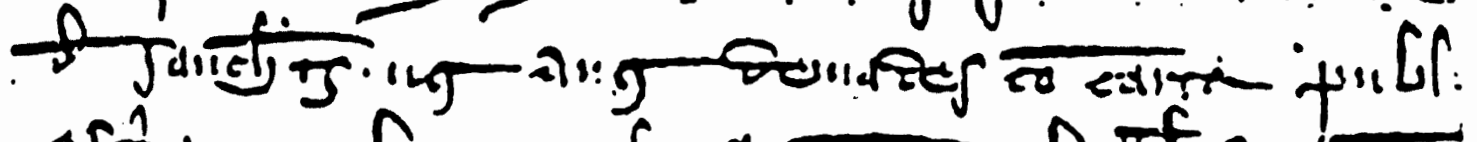

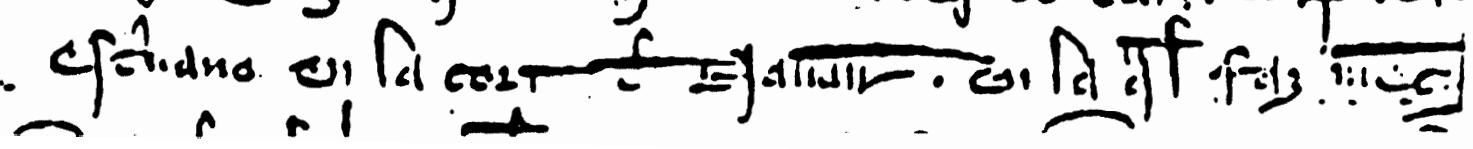

Doc. 6. 1302, abril, 7. AHN, O. M., San Juan, Navarra, carp. 072, núm. 19 (iné-

http://estudiosmedievales.revistas.csic.es 


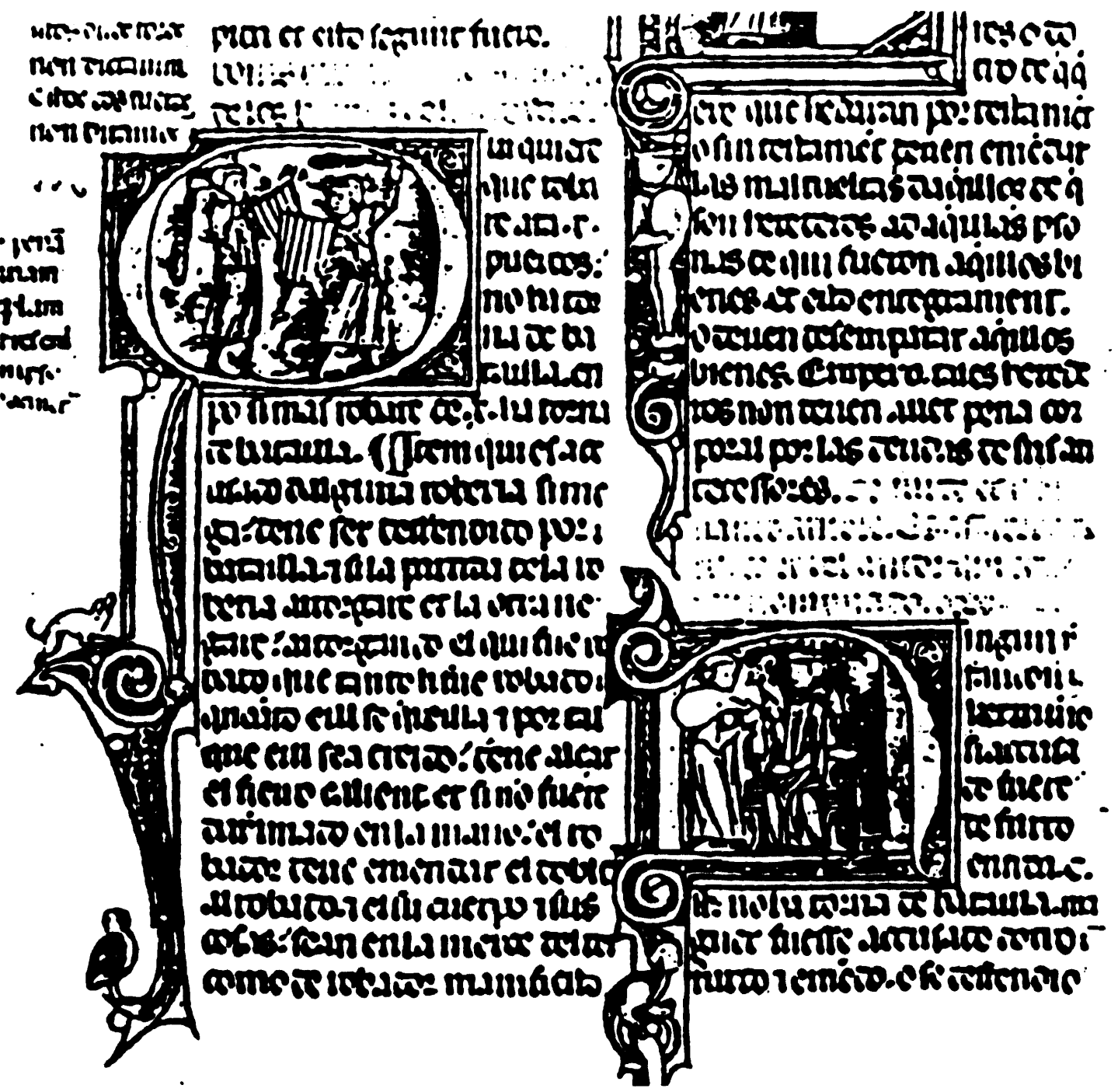

Doc. 7. Vidal Mayor.

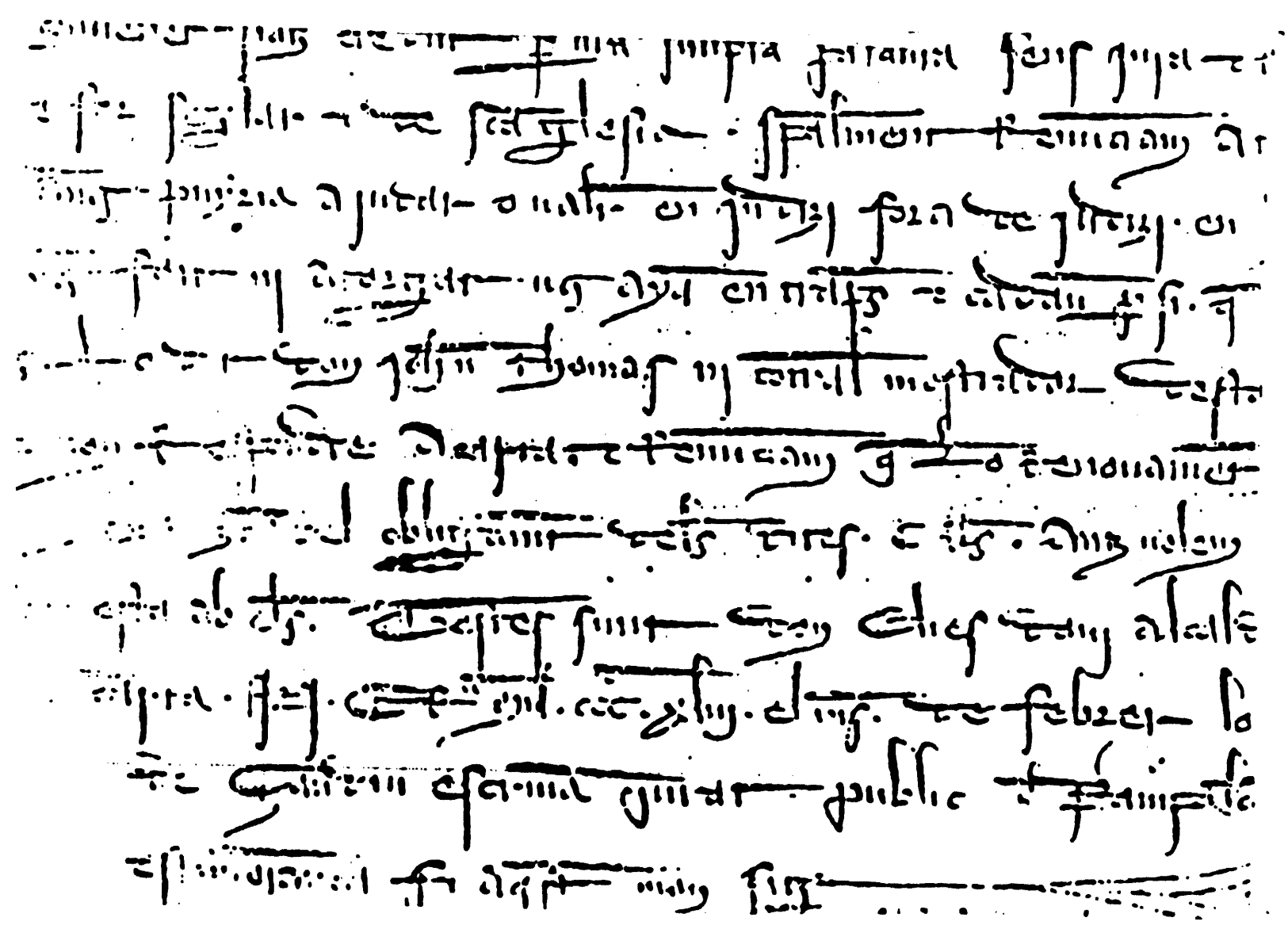

Doc. 8. 1305, febrero, 8. AGN, Clero, San Saturnino, núm. 128. Publ. García (c) Consejo Superior de Investigaciones Cientificas $\quad$ LARRAGUETA, Documentos, núm. 132. 


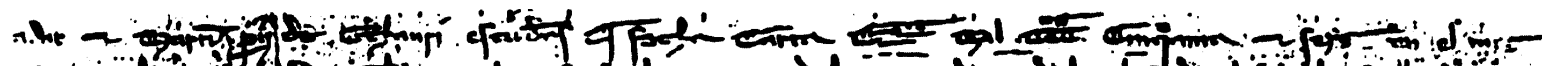
To

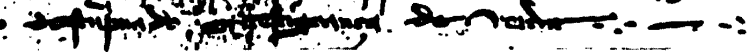

Doc. 9. 1318, mayo, 2. AGN, Clero, Roncesvalles, leg. 51, núm. 1209.

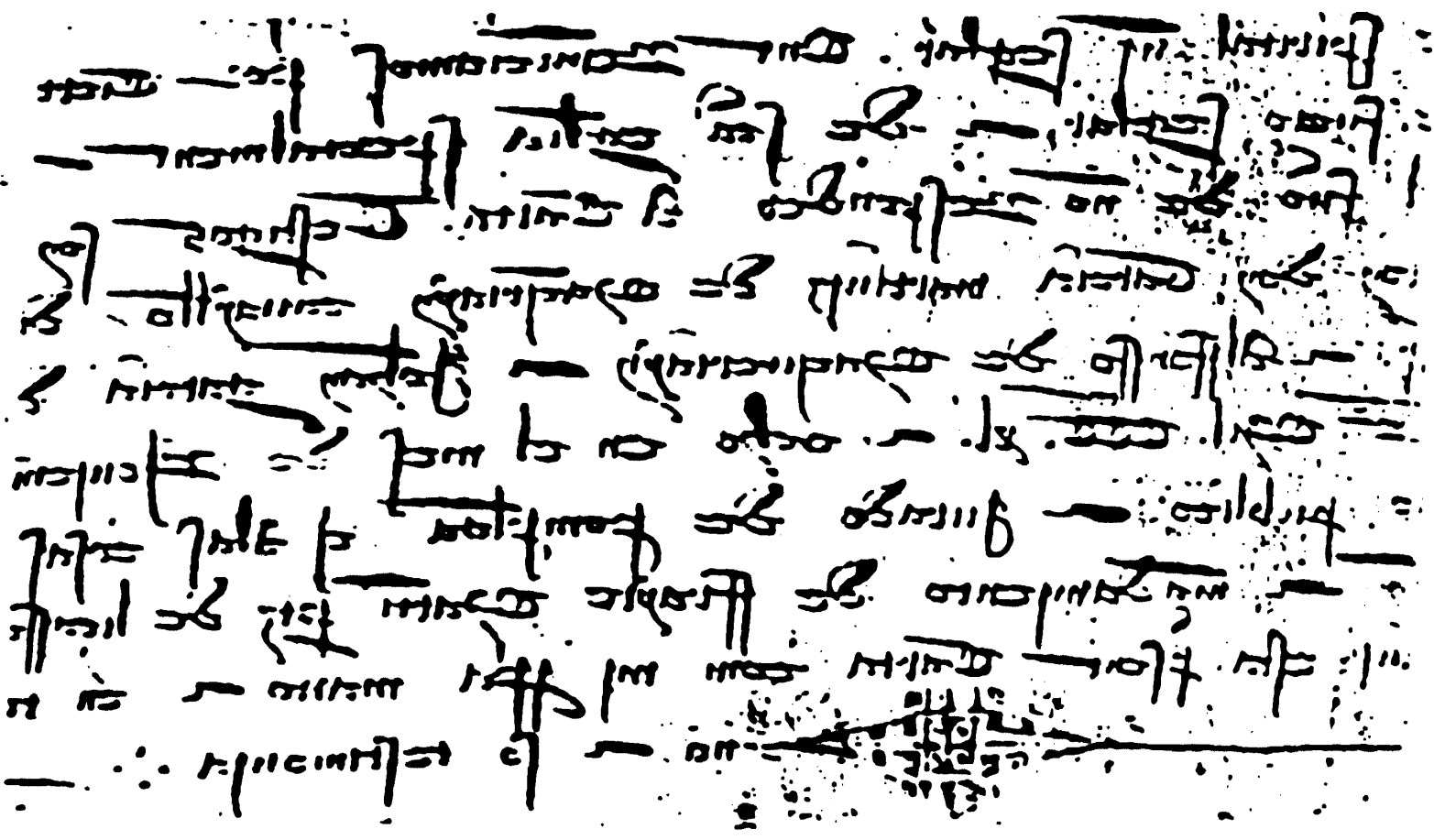

Doc. 10. 1310, nov., 4. AGN, Clero, Roncesvalles, leg. 82, núm. 1690. 
Tip of to tom som.

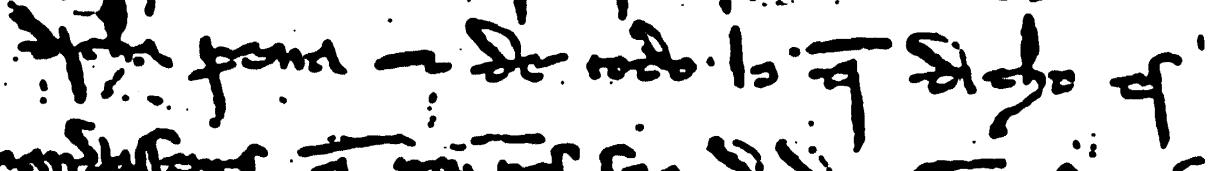

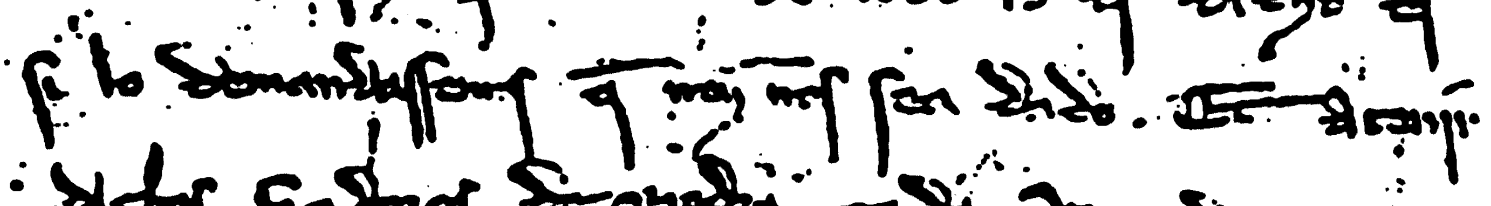

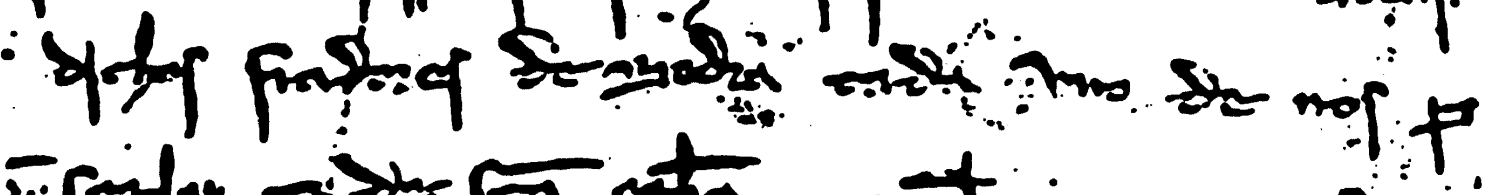

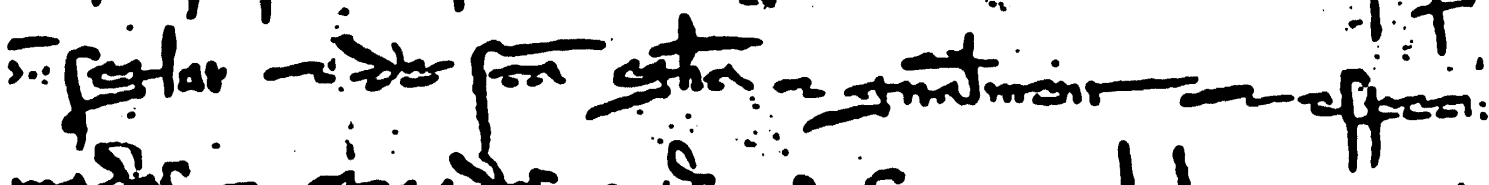

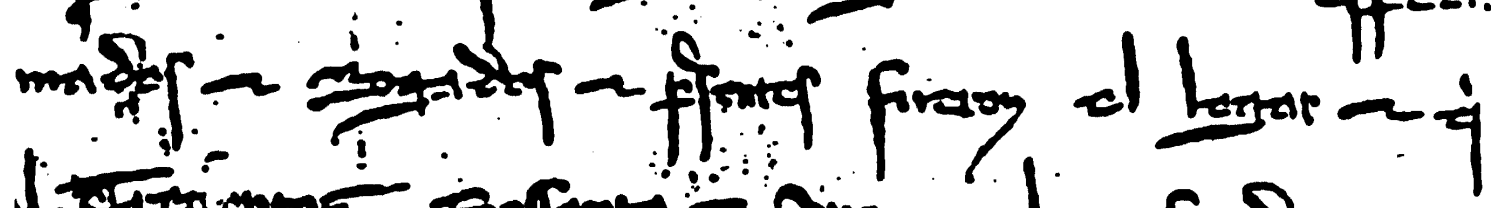

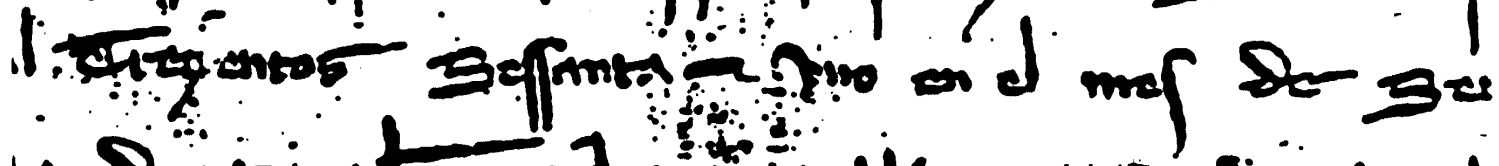

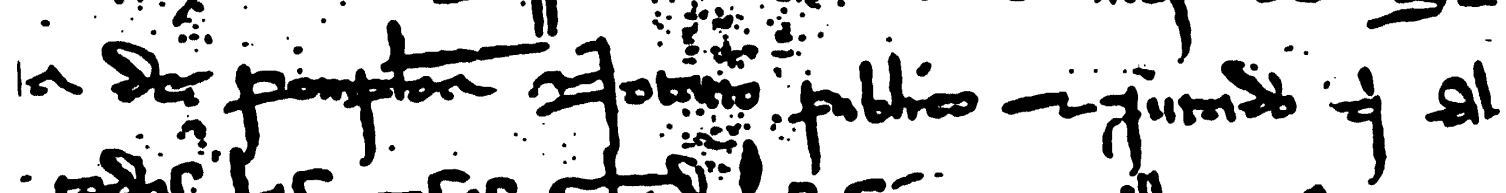

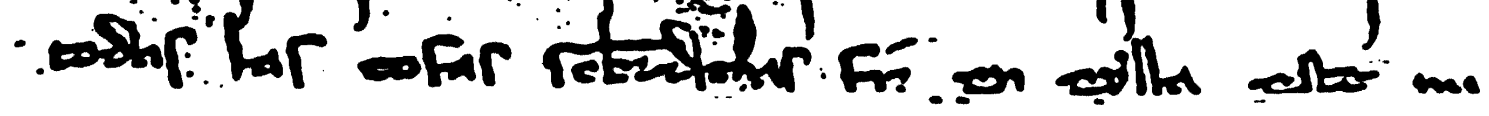

Doc. 11. 1323, sep. 21. AGN, Clero, Roncesvalles, leg. 50, núm. 1192.

Surom

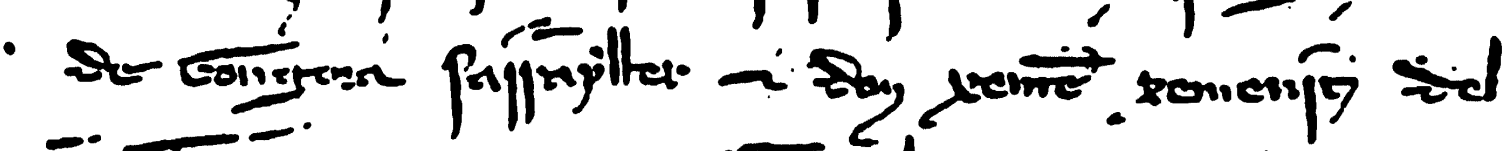

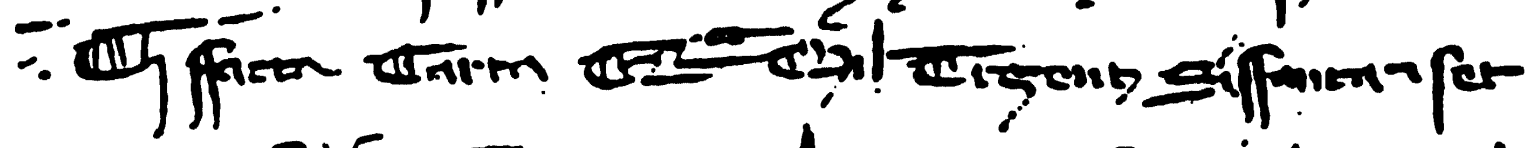

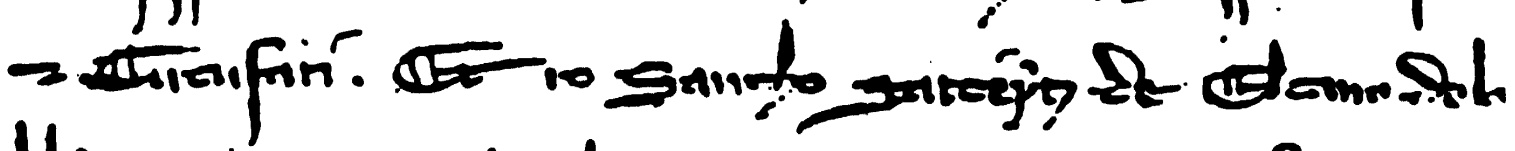

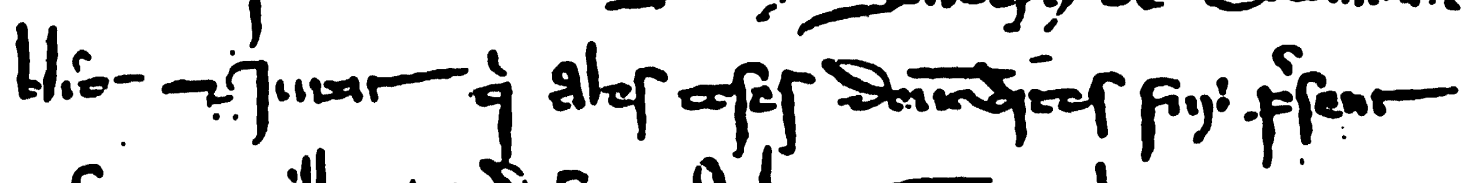

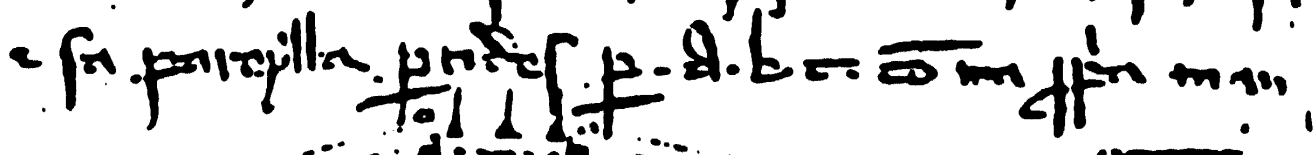
$\cdots$ Af Ant

Doc. 12. 1329, julio, 24. ACP, P. 34. Publ. García Larragueta, Documentos, núm. 228. 


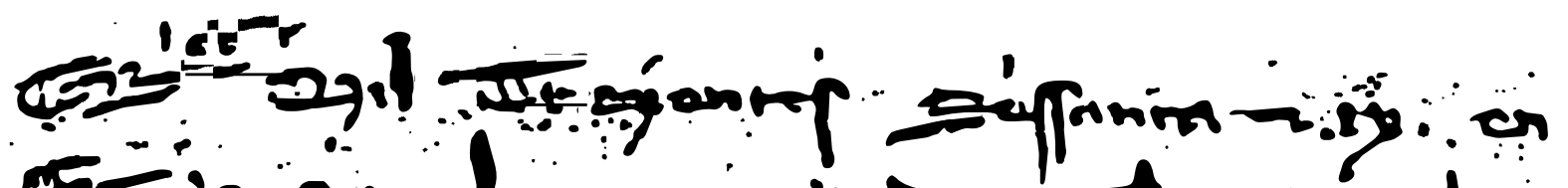

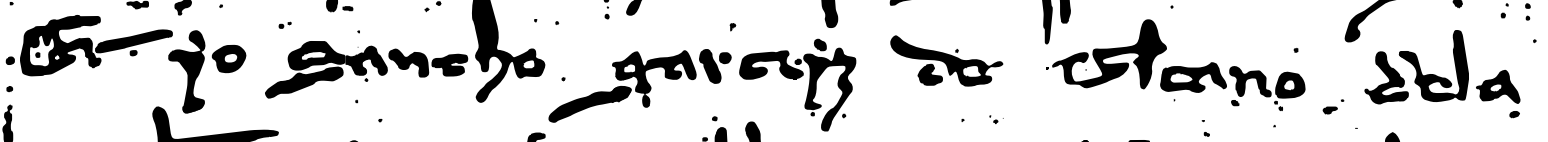

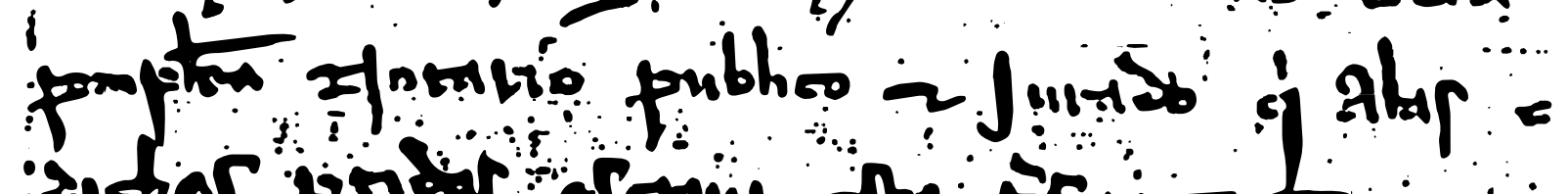

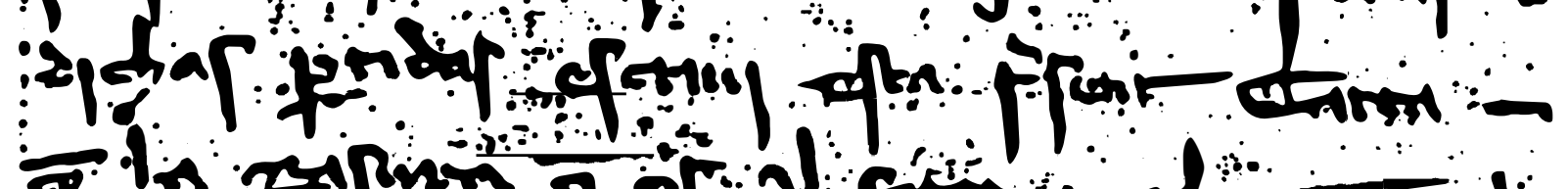

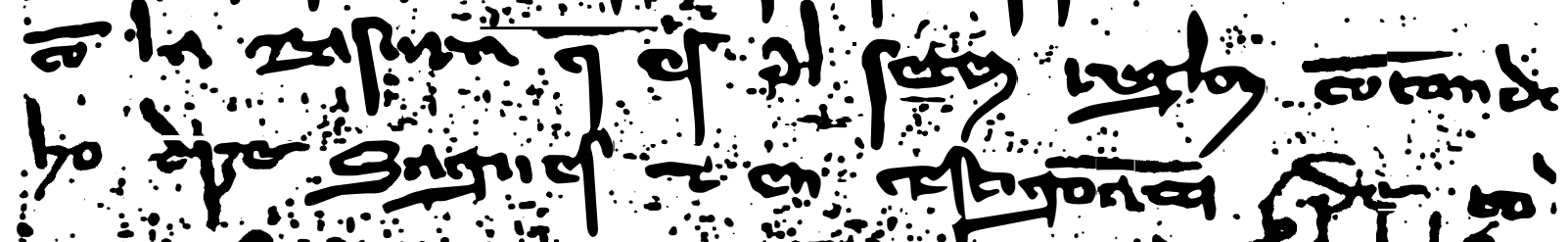
pinting

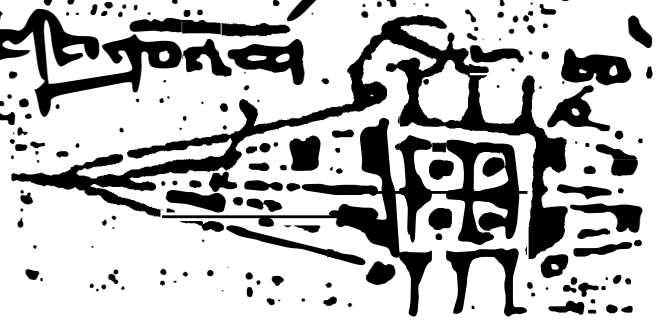

Doc. 13. 1331, abril, 2. AGN, Clero, Roncesvalles, leg. 49, núm. 1161.

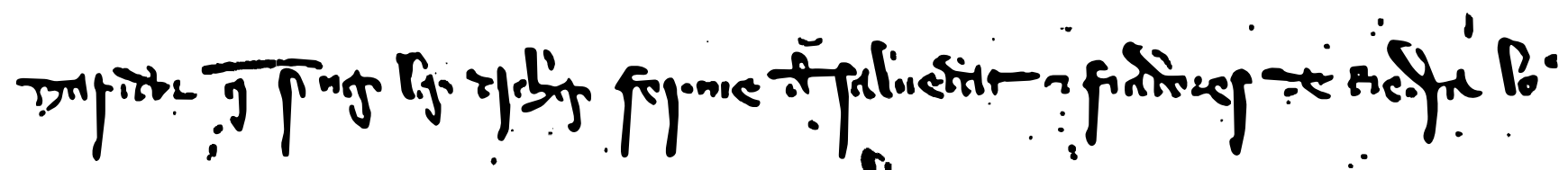

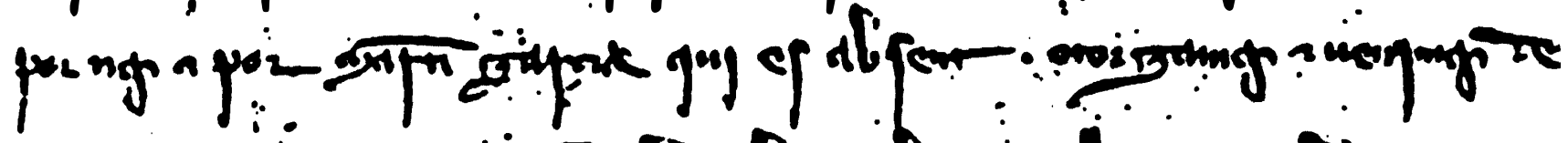

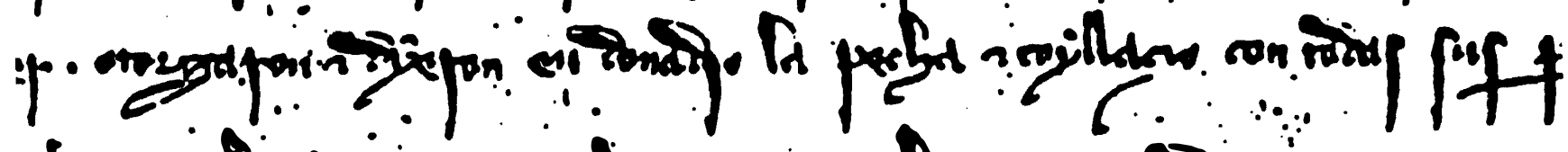

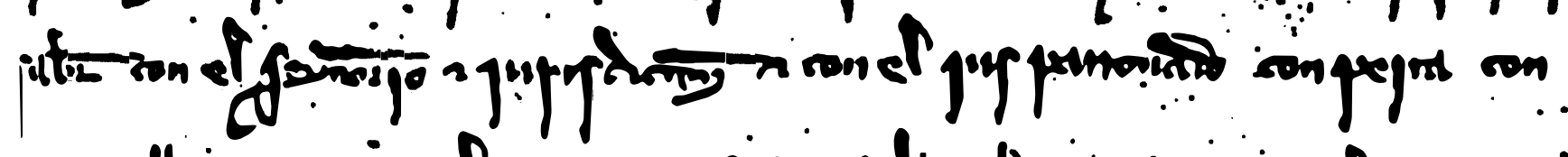

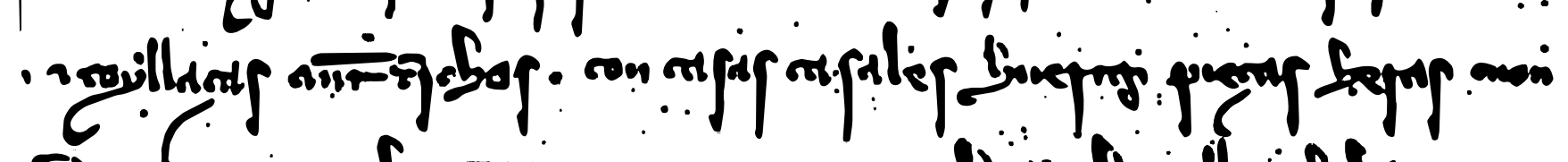

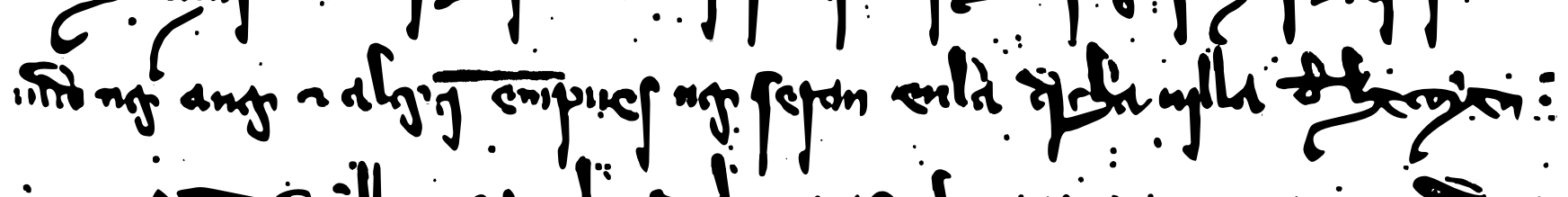

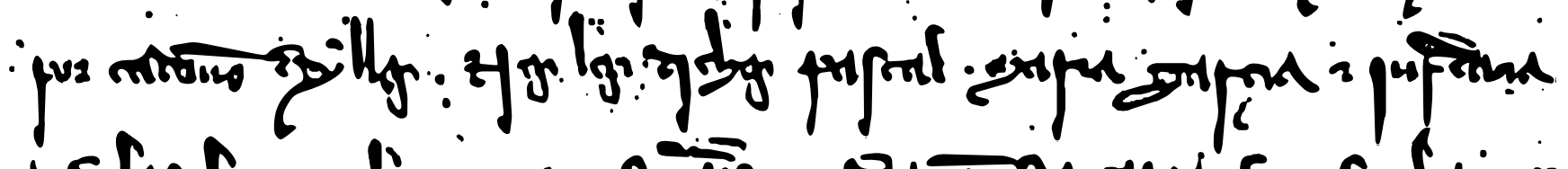

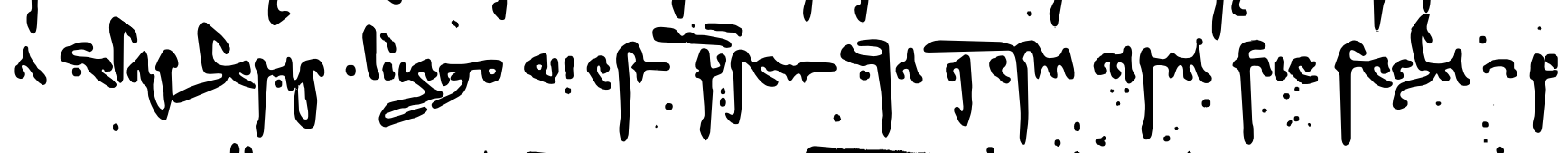

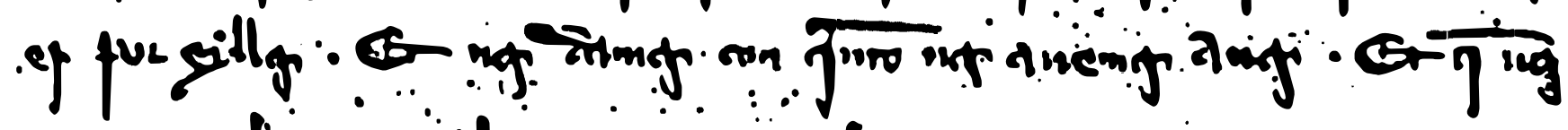

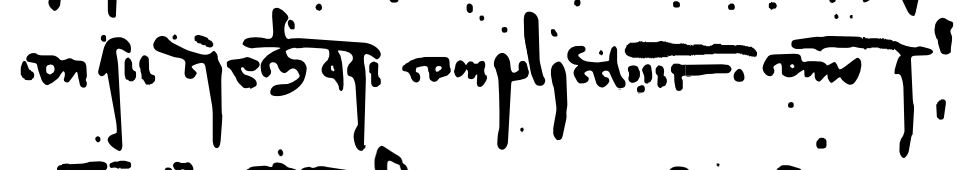
young renty 1 न

Doc. 14. 1321, nov., 10. AHN, OM, San Juan, Navarra, carp. 884, núm. 214 (c) Consejo Superior de Investigacio(eíá́áddițo). 


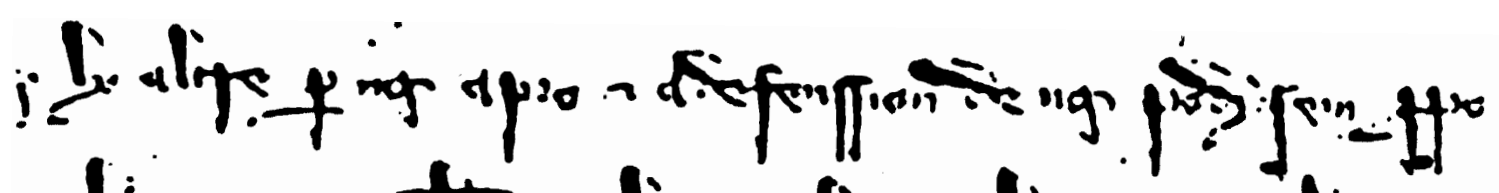

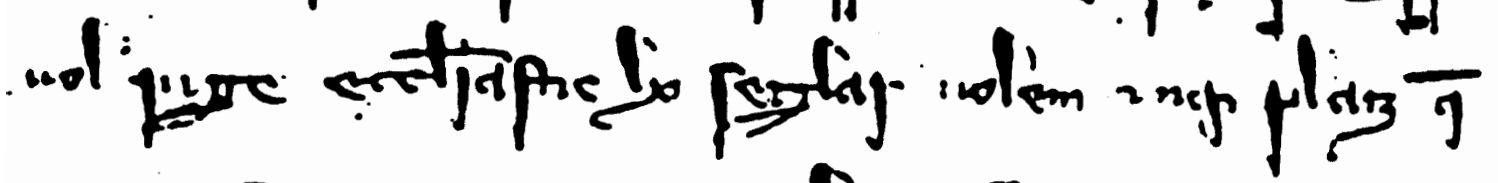

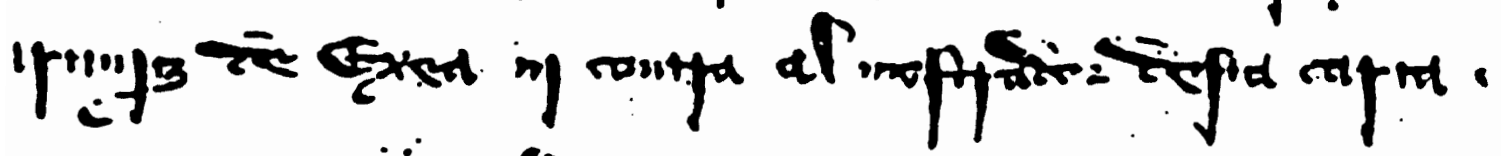

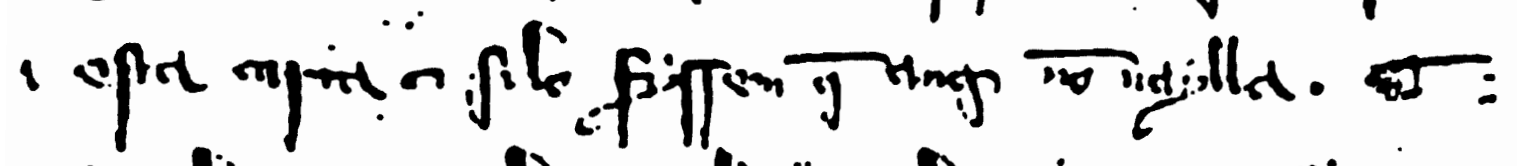

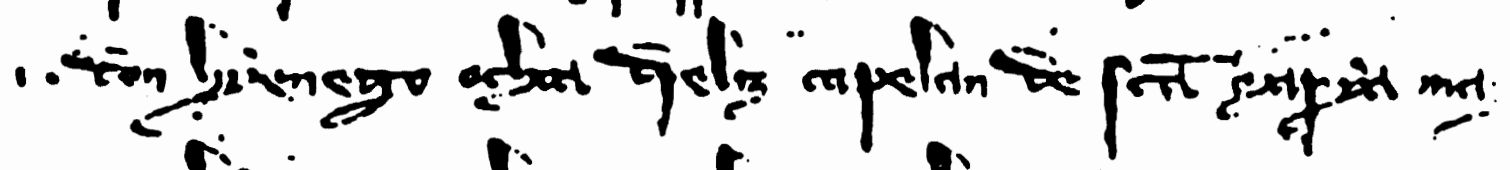
: $\rightarrow$ ti

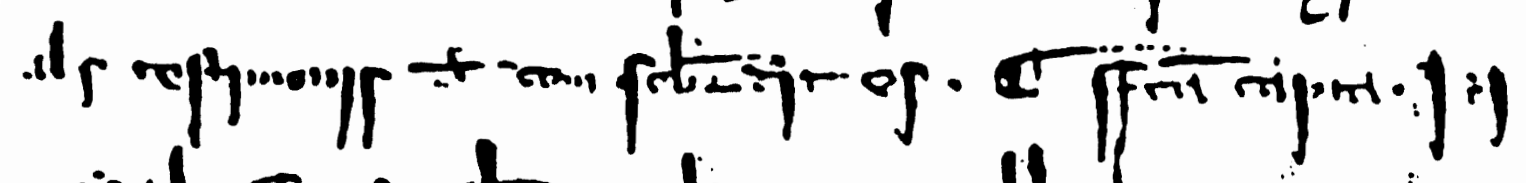

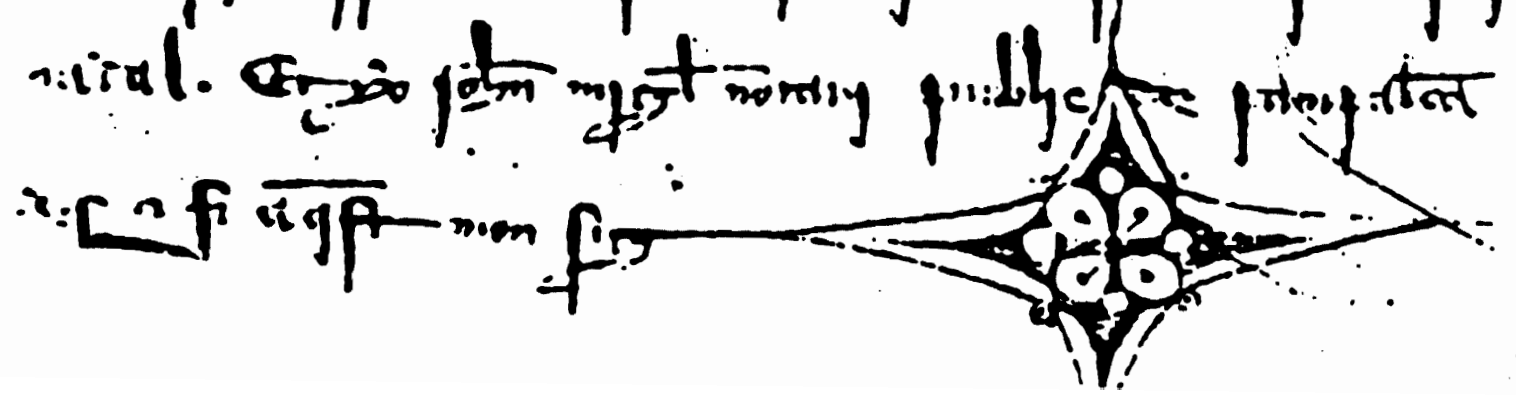

Doc. 15. 1325, dic., 22. ACP, P. 28. Publ. García Larragueta, Documentos, núm. 204.

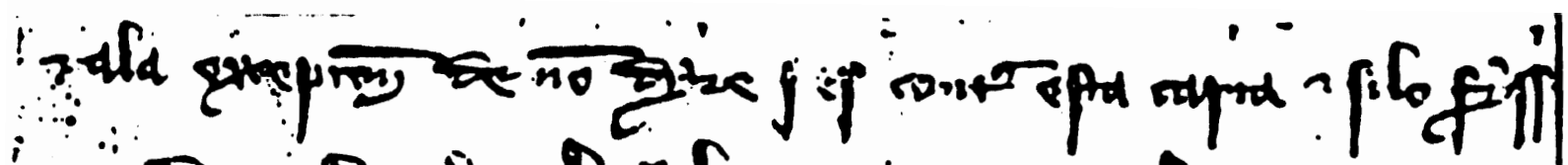

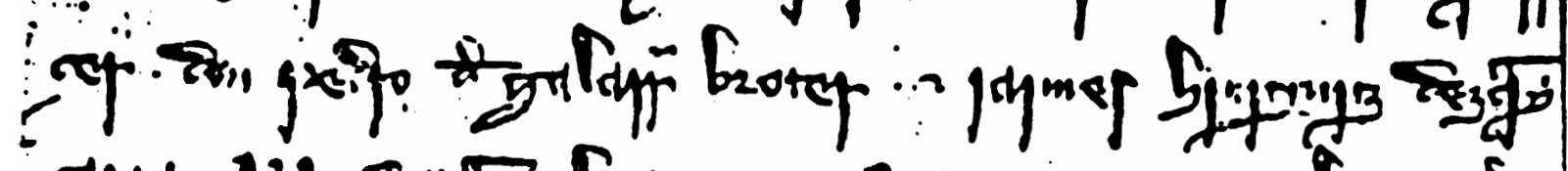

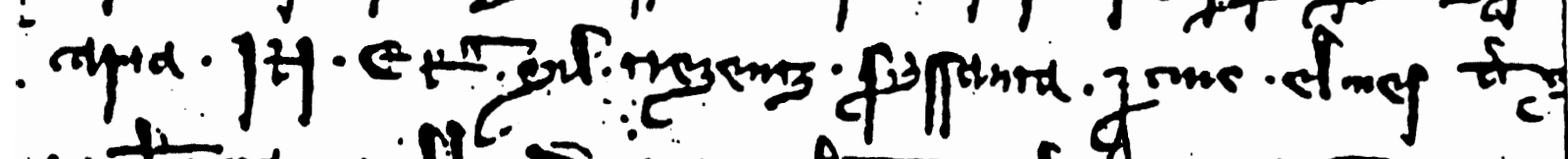

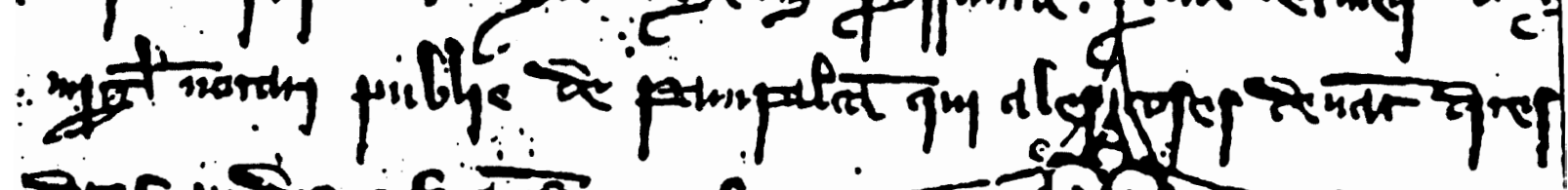
Dreffimat if a df monf

Doc. 16. 1327, mayo, 8. ACP, I, Hospit. 15. Publ. GarCía Larragueta, Documentos, núm. 209.

(c) Consejo Superior de Investigaciones Cientificas

Licencia Creative Commons
Reconocimiento 4.0 Internacional (CC BY 4.0)

http://estudiosmedievales.revistas.csic.es 


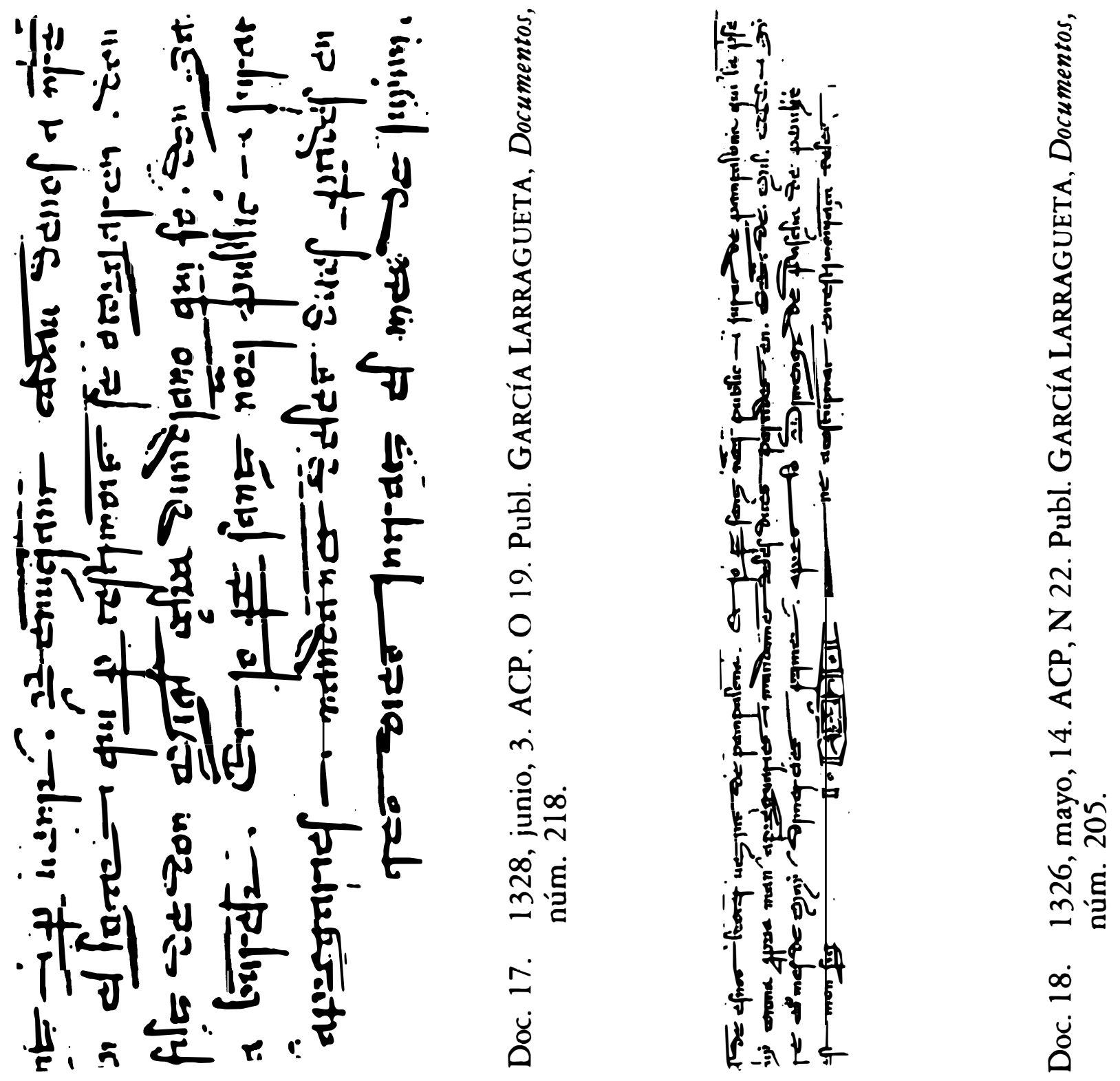

